COSMOPOLITAN COUNTY: MIGRANT FARM WORKERS' IMPACT ON THE AGRICULTURAL COMMUNITY OF LEAMINGTON

By

Brianna Jarvis, BA, University of Guelph, 2013

A Major Research Paper

presented to Ryerson University

in partial fulfillment of the requirements for the degree of

Master of Arts

in the Program of

Immigration and Settlement Studies

Toronto, Ontario, Canada, 2014

(C) Brianna Jarvis 2014 


\section{AUTHORS' DECLARATION FOR ELECTRONIC SUBMISSION OF A MAJOR RESEARCH PAPER (MRP)}

I hereby declare that I am the sole author of this Major Research Paper. This is a true copy of the MRP, including any required final revisions, as accepted by my examiners.

I authorize Ryerson University to lend this MRP to other institutions or individuals for the purpose of scholarly research.

I further authorize Ryerson University to reproduce this MRP by photocopying or by other means, in total or in part, at the request of other institutions or individuals for the purpose of scholarly research.

I understand that my MRP may be made electronically available to the public.

Brianna Jarvis 


\title{
COSMOPOLITAN COUNTY: MIGRANT FARM WORKERS' IMPACT ON THE AGRICULTURAL COMMUNITY OF LEAMINGTON
}

\author{
Brianna Jarvis \\ Master of Arts 2014 \\ Immigration and Settlement Studies \\ Ryerson University
}

\begin{abstract}
Migrant farm workers are the behind-the-scenes backbone of Canada's agricultural economy. Despite their significant role within the food production industry, the outer public is typically unfamiliar with their contributions, experiences, and even their presence in Canada. Many researchers agree that workers arriving through the Seasonal Agricultural Workers Program hold a precarious status, primarily due to the invisibility of their plight to the rest of Canada. In Leamington, Ontario, large-scale greenhouse operations call for thousands of workers from Mexico and the Caribbean to grow vegetables year-round. This study sought to gain an understanding of the relationship between migrant workers and community members by surveying and interviewing Leamington residents. While worker visibility and local familiarity with the presence of migrant workers is heightened in the Essex County region, the quality of social interactions was found to be severely limited. The implications were found to involve social marginalization, culture clash, and racial stereotyping.
\end{abstract}

\section{KEYWORDS}

Seasonal Agricultural Workers Program, social marginalization, culture clash, migrant labour, rural 


\section{ACKNOWLEDGEMENTS}

I would like to express my special appreciation to my MRP supervisor, Dr. Mustafa Koç, for his tremendous efforts to support and guide me throughout my research process. His contributions and advice have helped me grow as a researcher. I would like to also thank Dr. Mandana Vahabi for her input on my project as my second reader; their mentorship has been immensely appreciated. An entire year of endless support over long phone calls with my parents and sister meant the world to me as they pushed me to keep me going through this long process. I also would like to send a special thanks to my fiancé, who not only made the long road trip with me to Leamington, but also listened tirelessly when I bombarded him with my research plans, my findings, ideas, and of course my worries and stress. You are all wonderful and greatly appreciated. 


\section{TABLE OF CONTENTS}

Introduction

○ Research Objectives

○ Structure of the Paper 6

Backgrounder

○ The Prevalence of Temporary Labour, Explained 6

○ The Branches of the Temporary Foreign Worker Program in Canada 9

○ Introduction to the Seasonal Agricultural Workers Program 11

About Leamington $\quad 13$

Inequality, Invisibility, and Prejudice faced by Migrant Workers 19

○ Temporary Migration and Inequality 20

○ The Impacts of Inequality $\quad 21$

$\begin{array}{ll}\text { Research Methodology } & 27\end{array}$

○ Design $\quad 27$

○ Target Population 27

- Sample 28

- Ethical Considerations $\quad 29$

- Data Collection $\quad 29$

○ Data Analysis $\quad 30$

Findings $\quad 30$

Analysis of Findings $\quad 34$

○ Necessity of Farm Workers $\quad 34$

- Limited Contact between Locals and Migrants 38

○ Implications of Social Invisibility 41

○ Uptown Leamington $\quad 42$

○ Racial Stereotyping 43

$\begin{array}{ll}\text { Conclusion } & 46\end{array}$

○ Limitations $\quad 48$

○ Policy Recommendations $\quad 49$

○ Future Research $\quad 50$

LIST OF APPENDICES

$\begin{array}{ll}\text { Appendix A } & 53\end{array}$

Appendix B $\quad 55$

$\begin{array}{ll}\text { Appendix C } & 59\end{array}$

$\begin{array}{ll}\text { Reference List } & 60\end{array}$ 


\section{Introduction}

Canada has a rich and interesting history of an agricultural economy which has been shaped and laboured by many generations of migrant farmers and farm workers. Without the food that settler farmers managed to grow on unfamiliar soil in the earliest days of the country's history, entire communities of European settlers would have perished. The resiliency of immigrants was described by Chandler (2006), who wrote that if the crops failed, they did not eat. The government passed incentives with promises of fertile farmland to hopeful Europeans, who then faced obstacles of brutal winter weather and unresponsive crops as they shouldered the blame of the failure of new Canadian communities. In recent years, as the rural population declined, seasonal migrant labourers have been contributing to the vitality of Canada's agricultural economy. Farming, immigration, and the history of Canada have been inextricably linked.

The connection between Canadians and their food, and food production processes, have been closely intertwined. Over the decades, self-sufficient settler farming gave way to specialized simple commodity production by family farms. In recent decades, large-scale industrial farming has replaced the traditional family farms to a large extent (Koc, 2009). Rural Canadians would be familiar with several small family-run farms in their region being bought up to be incorporated into one massive farming business. Global exportation of specialty products such as wheat and beef ramped up the scale of production (Muller, 2008). Canada, like any other country, now imports a large proportion of food that is sold in grocery stores and exports many products to the global markets. Agriculture is a major industry that plays a significant role in Canada's economy. However, today there is a disconnection between food and the people who are responsible for growing it. 
The motivation for this project came from the concept of this disconnection. The local food movement has opened many Canadians' eyes to the importance of conscious consumerism in regards to food. However, existing research shows that Canadians generally have remained unaware of the existence and contributions of migrant workers in agriculture. The agricultural industry today relies on seasonal agricultural workers more than most Canadians realize. Sadly, migrant workers are largely invisible to the public, both physically and in terms of awareness of their working and living conditions. This study serves to explore the relationship between migrant workers and local residents, to situate the experiences of migrant farm workers in social reality.

Throughout the $20^{\text {th }}$ century, Canada diversified. Predominant self-sufficient family farming gave way to commodified specialized units producing for the market place under commodity pressures in the market. According to Statistics Canada, nine in 10 Canadians in 1851 lived in rural areas and earned their income from the primary sector such as agriculture [See Figure 1 (Canada's rural population, 2011) and Figure 2 (Rural Canada, n.d.)]. The Great Depression was probably one of the worst examples of the cycle of boom and bust, where farmers kept producing commodities for the market place to realize that all their efforts would seldom be sufficient to make a living (Muller, 2008). Census figures showed that about 50 percent of the population lived in rural areas in 1921. By 1976, this was less than 25 percent (Canada's rural population, 2011). Under commodity pressures created by an oligopsonistic market, farmers felt pressures to specialize, intensify and capitalize their production. Muller argues that a small number of farms grew progressively bigger and adopted more technology while smaller ones had to leave farming. As farmers purchased more land, they accrued more debt and had to reduce their labour cost by adopting mechanical technology to stay afloat. The 
small scale farm simply could not keep up to these pressures (Muller, 2008). Industrialization of farming allowed only larger and more efficient farms to survive while bigger corporations profited.

Over the years, cost-price pressures pushed smaller and diversified farmers out, and capitalized, specialized, and larger farms relying on hired labour and technology grew. Even this type of modern farm business has often struggled to make a decent return, despite the various types of support of programs offered by the state (Muller, 2008). Preibisch and Encalada (2010) noted that the rapid rise of corporate agriculture necessitated a cheap and flexible workforce. Industrial farms required reliable labour at a low cost to stay competitive, and this is where the Seasonal Agricultural Workers Program fits into the new reality of agriculture.

More and more Canadians live in cities and have become less and less informed about the conditions of production in the farm. They have become distanced from the farm, their food, and the farmers and farm workers who labour for their food. The emerging 'local food movement' tries to problematize distancing, questions the sustainability of the globalization of the food system, and encourages consumers to seek local foods produced by local farmers. Trivette (2012) argues that locally produced food is good for the environment, improves the local economy, and ultimately provides a greater connection between people, their food, and those who produce it. The popularity of the 100-mile diet was an indicator of greater attention to food's sustainability (New TV series, 2009). British Columbia planned to spend $\$ 3$ million in 2008 to increase residents' awareness of the mileage behind their food, in a campaign to encourage local food (Keller and Patten, 2008). Another part of the local food movement is the rise in popularity of farmers' markets. In the United States, purchases directly from food growers were reportedly worth $\$ 1.2$ billion in 2007 and they continue to grow (Long and Murray, 2013). 
In Edmonton, the downtown farmers market in two years boomed from 8,000 frequenters to 16,000 in 2009 (Pratt, 2009). The St Jacobs Market in Waterloo, Ontario is not insignificant either, as it "[...] attracts thousands of tourists each week to the Waterloo Region and provides a livelihood for local farmers, cooks, and craftspeople" (Gordon, 2013). Indeed, farmers' markets can be a major contributor to the local economy. In Vancouver, the 'Your Local Farmers' Market Society' was presented with an award for Community Economic Development for just that reason (Recognizing farmers' markets, 2001).

The steady growth of the local food movement in recent years also reflects a shift in attention of Canadian consumers. One might assume that the public's interest in local foods indicates that the gap between the consumer and the grower is closing. Unfortunately, there seems to be little awareness among the consumer about the conditions of production, about the challenges farmers face, and about the difficulties of farm work. While the consumer may be focusing on the idea that the food is local, local does not necessarily mean that the food is produced under fair and just conditions. The consumer who is motivated by moral beliefs is typically distressed about the environmental impact of buying food with a large ecological footprint (Pratt, 2009; Vermeir and Verbeke, 2006). The preoccupation with the environmental impact of one's food overlooks the impact of the treatment of temporary migrant workers who grow food in Canada's own backyard. Migrant Caribbean and Mexican workers represented 53 percent of employees in the horticulture sector in the year 2000 (Brem, 2006).

Despite their significant contributions across Canada's agricultural industries, temporary migrant farm workers are often overlooked. Lack of media attention as well as the nature of their 'behind-the-scenes' work causes a problematic invisibility are among the causes of their invisibility for migrant workers. According to existing literature, migrant farm workers live both 
literally and figuratively on the outskirts of society (Mysyk et al, 2009; Preibisch, 2004). As a result, well-intentioned consumers appear to be generally unaware of the role played by migrant workers in Canadian agriculture as well as the difficulties they face.

\section{Research Objectives}

This research is driven by the basic idea that migrant farm workers do not receive significant attention from the public (Read et al, 2013). In a country where an increasing number of consumers are making local and sustainable food choices, one wonders if there is sufficient research about the conditions of foreign farm workers who labour for the local food in Ontario.

The goal of the research is to gain a clearer understanding of the relationship between Canadians and migrant farm workers. In communities that are more urban, or those far removed from the farms that house and employ migrant workers, people are much less likely to have ever interacted with a migrant farm worker (Preibisch, 2004). However, some communities have closer ties with agriculture. In such towns, the barriers between migrant workers and Canadians are lessened (Preibisch, 2004). Leamington, Ontario was chosen as the study location in order to best explore the opinions, attitudes, and awareness levels of Canadians towards temporary farm workers.

Through a set of interviews with local residents of Leamington, who are not directly involved with the farming industry, I seek to provide insight on the nature of their social relationships with seasonal farm workers. The research question asks how they conceptualize not only the migrant workers, but their community considering the presence of migrant workers. This project seeks to be a step toward better understanding Leamington residents' awareness and opinions towards the role of migrant farm workers in their food and in their country.

What is the significance of this research? Researchers and the media have pointed out the struggles of adapting to precarious work situations, policy issues, and cultural clashes, among 
other dysfunctional aspects of the Seasonal Agricultural Workers Program (Read et al, 2013; Sahoye, 2013). While a voice has been given to workers through academic research, there remains a lack of data about the problems and reality of the migrant farm worker program from the perspective of Canadian community members. Collecting accounts of the day-to-day reality of Leamington, Ontario could provide valuable insight into social issues, improvements necessary within the Seasonal Agricultural Workers Program policy, the harm that stems from a lack of community integration, and places where solutions could be implemented. Approaching this project through the lens of the community will provide vital insight about changes that could be made to better the relationship between workers and locals. Ideally, a clearer picture of the reality of the oftentimes controversial program would be portrayed.

\section{Structure of the Paper}

First, an introduction to the conditions of the Temporary Foreign Worker Program including the Seasonal Agricultural Workers Program in Canada will be provided to ground the research in legal-political context. Next, there will be a discussion of Leamington in terms of its history as well as its social and economic reality in the present day. Following that, a review of existing literature will explore the topic of migrant relationships with the outside community. Then, this study's research methodology will preface the research findings and analysis of said findings. The conclusion will summarize the knowledge that was gained through this exploratory research paper.

\section{Backgrounder}

\section{The Prevalence of Temporary Labour, Explained}

In order to situate and understand the position seasonal agricultural workers hold in Canada, it is important to understand the drivers of the trend that resulted in them becoming so 
prominent in the agricultural industry. Researchers agree that Canada's immigration policy has, in recent years, ceased to provide paths to citizenship for many kinds of applicants. Today, the dramatic shift in policy has so strongly impacted the immigration system that by 2008 , the number of temporary foreign workers surpassed the number of permanent residents admitted into the country (Canadian Counsel for Refugees, 2010). Canada, from an economic standpoint, is hooked on temporary labour.

The literature conveys the idea that a mutual dependency has ensured the continued reliance on temporary foreign labour (Perry, 2012). The migrant-sending countries of Mexico and various Caribbean nations are dependent on the economic stimulation provided by their neighbors to the north. The role of certain policies, including the Memorandums of Understanding between the migrant-receiving and migrant-sending countries and especially the North American Free Trade Agreement (NAFTA) have legislated a power imbalance between what is called the Global North and the Global South. Globalization launched the prioritization of deregulation and free capital (Koc, 2012). Chaccon (2011) placed responsibility on NAFTA, as well as World Bank structural adjustment development strategies which indebted Global South countries, for sparking new migration patterns. Millions of Central Americans and Caribbean people lost their social and economic footing thanks to the implementation of oppressive policy. The power imbalance existing due to structural inequalities between developed and developing countries was amplified, creating a desperate and vulnerable workforce coming from the Global South. Walia described the labour pool as a perfect workforce in the new era of labour relations, because it was "commodified and exploitable, flexible and expendable" (2010:72). The reason the workforce became ideal in today's global capital-labour relations is due to the dependency on economic stimulation provided by Global 
North nations such as Canada and the United States. Mainly, that stimulation comes in the form of remittances. The World Bank estimated that approximately US $\$ 4$ billion was sent to China, along with $\$ 3$ billion to India and $\$ 2$ billion to the Philippines through remittances from Canada by immigrants and temporary foreign workers in 2012 alone (Pang, 2013). Developing countries with significant amounts of emigrants count on remittances as foreign revenue. Individuals who support their family members by sending money home frequently are providing a reliable financial resource for their home country.

Aside from establishing that various systemic and structural power imbalances ensure Caribbean and Mexican workers remain dependent on temporary labour, researchers also explore the factors that contribute to Canada's relatively new dependency on temporary labour. The literature confirms that Canada has restructured its immigration policy around its preference for temporary labour. The restructuring or modernization of Canadian industries such as agri-food production necessitated changes in the way workers are incorporated into wage labour (Preibisch, 2007:420). Furthermore, experts and critics explain that Canada's economy undeniably benefits from this strategy. Whereas prior to the availability of foreign labour, businesses would have to increase wages to incentivize unwilling locals, Worswick explains the appeal of alternative options that render such strategies unnecessary. He asserts that having access to a temporary foreign workforce alleviates the need to raise wages in order to attract local workers (2010:5). Thus, programs like the SAWP become crucial for the survival of farmers who are facing commodity pressures from corporations controlling the input and output market and must lower their cost of production to stay afloat (Wiebe in Koc et al, 2012). Hennebry and Preibisch (2010) credit temporary migrant workers as a main factor in the continued success of the Canadian agricultural industry. The literature appears to share the view 
that the economic benefit to the government and to business owners of a disposable, inexpensive, and exploitable workforce is unparalleled. The federal government defends its pro-temporary migration stance in a report describing the ways in which Canada benefits from the TFWP. "Section 2(1) of the IRPA states that the first objective of Canada's immigration policy is 'to permit Canada to pursue the maximum social, cultural and economic benefits of immigration.' Like all OECD countries, Canada relies increasingly on the temporary residents to fulfill its immediate labour market requirements and to remain competitive internationally. The temporary aspect of the Temporary Foreign Worker Program may also help to avert major costs related to unemployment during a recession or periods of slow economic growth" (Pang, 2013: Section 5.1).

The statement represents Parliament's response to critics of the program who argue that temporary workers should not serve to replace a more costly Canadian employee, those who believe that all workers should have the right to permanent residency, and to those who view the TFWP as too risky from a human rights perspective. Essentially, the statement clarifies that immigration does not exist primarily for compassionate, humanitarian purposes. Canada settled on the TFWP because of its effectiveness in bolstering the economy at a comparably low cost compared to importing permanent labour.

\section{The Branches of the Temporary Foreign Workers Program in Canada}

The people who grow food today in Canada are very likely to be temporary migrant workers. This year, temporary migrant workers nearly became a buzzword in newspapers as Canadians realized just how prevalent this type of labour is in many industries. The discussion of migrant workers rose to popularity as it is a controversial and complex topic. The Temporary Foreign Workers Program is the umbrella term for separate temporary labour programs 
implemented by the federal government. Generally, they are grouped into three different programs.

The first is possibly the most well-known program thanks to attention from governmental policy-makers and especially the media. It is known as generally as the temporary foreign workers program, which incorporates both the low and high-skill occupations. It includes both post-secondary educated workers and artistic entertainers, but the most prevalent discussions in the news are in regards to the fast-food workers and other low skill workers. In 2013, three McDonald's restaurants in British Colombia were brought under fire for abusing the temporary workers program's regulations (Mas, 2014). The investigation sparked national media attention and provided Canadians insight into the regulations and issues of the TFWP.

The second branch of the program is the Live-in Caregiver Program. The Live-in Caregiver Program may be familiar to Canadians living in wealthier urban neighborhoods. Most Canadians associate this program with Filipina women who are employed as caregivers colloquially referred to as nannies - for Canadian families' children. This program allows individual families to apply to hire a caregiver from overseas, who will then live with the family for a minimum of two years to take care of the children. After 24 months of work, the live-in caregiver is permitted to apply for permanent residency to end their temporary status within Canada.

The Seasonal Agricultural Workers' Program is the last branch of the TFWP. The workers who arrive specifically through this program are central to this project. The Seasonal Agricultural Workers' Program is the formal route for Canadian farmers who lack an adequate amount of local labourers. The workers traditionally arrive from Caribbean sending countries as well as Mexico (Pang, 2013). Out of the entire TFWP, only 8 per cent of workers were employed 
through the SAWP (Pang, 2013). They are permitted to stay in Canada for the duration of the growing season and then return home to their own country. Unlike in certain versions of the temporary foreign workers program, as well as the Live-in Caregiver Program, seasonal agricultural workers have no official pathway to gaining permanent residency.

\section{Introduction to the Seasonal Agricultural Workers Program}

The realities of agricultural work in Canada today stand in stark contrast to the historical position of farmers. Farm work was traditionally revered as virtuous. Farmers who worked the rural landscape were not only perceived as exempt from the sins and corruption of the city, but were viewed as living their lives according to God and morality (Parr, 1994). Such beliefs are indeed outdated today. If the philosophy still stands, it has long since ceased persuading the average Canadian to commit to agricultural work. The fact that Canadians are typically unwilling to do manual agricultural labour was the catalyst for the creation of the Seasonal Agricultural Workers Program in the 1960s (Binford, 2006).

What makes Canadians reluctant to participate in agricultural labour? Hennebry and Preibisch (2010:23) lumped agricultural labour in with the 'three D' jobs: dirty, dangerous, and difficult employment. It is undeniably dangerous, as there are 115 fatalities and 1,500 serious injuries due to farming accidents annually in Canada (Mysyk et al., 2009:319). The aversion Canadians share towards the challenging form of manual labour became clear after the 1950s when farmers in southwestern Ontario began complaining that they could not find committed labourers for their growing seasons. The trend has continued. Even Canadians who are desperate for employment are not desperate enough to commit to a season of farm labour in unappealing conditions and for low wages (McLaughlin, 2009). One privilege of holding permanent status in Canada is the ability to opt out of such work, and access employment insurance instead. Anecdotal evidence of the unwillingness of citizens to work such jobs comes from North 
Carolina in 2011, where 7,000 manual agricultural jobs were offered to unemployed citizens (Clemens, 2012). Out of the 250 applicants, only 70 had not quit after the first day of work, and only five remained after a few weeks. From evidence like this, it is evident that farmers do not have a lot of options, as wages are unlikely to change. Farm operators and government officials agree that a wage increase would negatively impact the agricultural industry by driving up the cost of food (Brem, 2006). Canada's agricultural economy will continue to thrive on low-wage labour.

To alleviate the labour shortage, a program was created that sourced much-needed labour from the reserve of offshore workers from the Caribbean. Despite the fact that other Commonwealth nations and the United States had each implemented guest worker programs, it took years for farmers to convince bureaucrats to agree to create a program. Initially, the government denied continued request for a Caribbean solution to the labour shortage, arguing that they preferred to look into recruiting other low-skill groups from Canada itself, and later suggested European immigrants as a solution (McLaughlin, 2009). When the Seasonal Agricultural Workers Program became active in 1966, the legislation emphasized the temporary status of the workers: "[...] there remains the question of their support during the winter months [...] It is extremely unlikely that the Canadian economy could continue to absorb such a stream of unskilled workers over the long run" (2009:134). And thus the strictly temporary status of workers in the SAWP was established. Many workers return to Canada on renewed contracts by being named by the same employer year after year, sometimes for decades. However, agriculture is seasonal work, and the workers remain permanently temporary because of their lack of employability in the offseason (Basok and Binford, 2004). The prevailing attitude towards the 
SAWP today remains identical to these sentiments, and the motivation behind them has not changed either.

Leamington and St. Catharines were the first destination for the 264 successful Jamaican workers out of 1,500 applicants in the inaugural SAWP growing season in 1966 (McLaughlin, 2009). The program saw such immediate success with Jamaican and other Caribbean workers that many other countries sought to create similar Memorandums of Understanding with the Canadian government. However, requests were routinely denied until Mexico was made an exception in 1974 as a method of halting labour negotiations with Caribbean sending countries (McLaughlin, 2009). Representatives of the Caribbean growers began making demands to the program officials on the basis of emerging knowledge of poor working conditions and low pay. The Canadian government had a high amount of interest in the program from other countries; which gave them the ability to not only ignore the demands, but gave Caribbean representatives an ultimatum. In order to increase the competition, Canada opened the program to Mexico. It served the purpose of sending a message that the supply of workers was so massive that negotiators no longer had any power. Today, the majority of workers coming to Canada are from Jamaica, St Lucia, and Mexico.

\section{About Leamington}

Leamington was chosen as the location for this study due to several factors. With the seemingly constant presence of the Temporary Foreign Workers Program in the media, the public's attention is turned to the future of Canada's employment policies. In these times, Leamington emerges as a meaningful case study. The government has been controversially restrictive with the data regarding Essex County's exact number of temporary foreign workers, but it is common knowledge that the region hosts a significant proportion of Ontario's 16,000 
annual migrant workers (Brownell, 2014, Shreve, 2014). Furthermore, Leamington was one of the two test sites for the inaugural year of the SAWP (McLaughlin, 2009).

Leamington makes an ideal research site due its residents' familiarity with the SAWP. Elsewhere, farmers' use of seasonal agricultural workers tends to be obscured from the view of the public. However, agriculture has fueled Leamington's economy for more than a century. The town is known as the Tomato Capital and the Greenhouse Capital of Canada. The close proximity of major farming operations to the city center allows for a unique level of visibility for the workers, who are a commonplace presence around Leamington. The combination of uncertainty in employment, as well as the transparent presence of temporary foreign workers, yields an interesting collection of public opinions from local residents.

The research for this project occurred in Leamington, Ontario. The municipality of Leamington had a population of just over 26,500 in 2011 (National Household Survey, 2011). The town of Leamington has a history of immigration. It was established in 1890 (Davidson and Davidson, 2009). From World War II onwards, waves of immigrants had arrived to settle in the town, including Germans, Mennonites, Italians, and Portuguese people (Basok, 2002, National Household Survey, 2011). At present, just over a quarter of residents in Leamington are foreignborn (National Household Survey, 2011). Unfortunately, the government is not forthcoming with specific data on the temporary foreign worker population.

The history of Essex County begins with First Nations. Leamington today stands on former marshland, which was neutral territory. The surrounding area originally was occupied by Ottawa, Petun, Chippewa, and Huron First Nations (Clarke, 2002, Native Territories, 2006). On May $21^{\text {st }}, 1790$, the sale of a huge area of southwestern Ontario land was made from the First Nations to the British (Clarke, 2002). The cessation was controversial as the superintendent of 
Indian Affairs had purchased the land without consultation to the Land Board, who argued that the land was poorly chosen. The Ottawa and Chippewa "did not play, hunt, or camp on it" (Clarke, 2002:126). Today, the Caldwell First Nations are the only First Nations community based in Essex County.

The wetlands that covered the entire area save for slivers of ideal farmland near the shores of Lake Erie prevented extensive settlement for quite some time (Clarke and Brown, 1981). According to Clarke, when surveyors charted the land in the late $1700 \mathrm{~s}$, more than 70 percent out of the 452,480 acres of land was poorly drained (2002:3). Today, the marshes are primarily limited to Point Pelee National Park, proving a formidable advance in agricultural technology that allowed soil to drain and become functional. Furthermore, Essex County represents one of the top most productive agricultural regions of Canada today. According to the Essex County Federation of Agriculture, in 2006 there were 1,235.5 acres of land under glass in Essex County and a total of 1,740 farms (Agricultural Facts, 2009).

In 1792, Governor Simcoe made Essex the $18^{\text {th }}$ of 19 counties in Upper Canada (Early Municipal History, 2014). The first European settlers in Essex were French, Pennsylvania Dutch Mennonites, and Hessians, who were German soldiers contracted by the British government (Early Municipal History, 2014). Initially, Amherstburg and Sandwich were the first settlements in Essex. The construction of Talbot Road (now Highway 3), named for Colonel Talbot who spearheaded the regions' development, occurred during the War of 1812 and was finished in 1818. Settlers began living in Leamington in the 1820s. The potato famine in Ireland caused mass migration to Essex County. Leamington was also a major location along the Underground Railroad for escaped black slaves from the southern United States (Early Municipal History, 2014). In Figure 3, a map of Essex County's location in Ontario is provided, followed by Figure 
4 which illustrates the towns in Essex County (See Appendix A). The history of Leamington indicates a foundation in diversity and different cultures. However, it is important to note that Leamington's diversity is of a specific variety: both historical and recent immigrant groups have predominantly European heritage. There is diversity, but it is mainly limited to ethnic groups of European descent. This fact indicates that despite a history of diversity, the presence of visible minorities has not been prevalent throughout Leamington's history. Mexican and Caribbean workers remain standouts amongst the population of White residents of the rural town.

In the initial stages of building this study, the departure of the Heinz manufacturing plant from Leamington was included as a potential factor that could influence participants' opinion of the SAWP. The town's biggest employer was about to disappear, and layoffs were imminent. The future of employment in Leamington had suddenly become uncertain. The national media reported the announcement and conveyed that Leamington residents were highly concerned about the town's future. Considering the major presence of migrant workers in Essex County, could the newly unemployed foster resentment or newfound xenophobic attitudes towards the temporary labourers? This sentiment was extrapolated from the 'immigrants are stealing our jobs' mentality that is commonly echoed by Conservative Americans in the media. The opportunity to investigate the ways that community members conceptualize the role of migrant workers in the face of Leamington's faltering economy presented itself. Despite the likelihood that Heinz workers were seen as highly skilled and higher paid than uneducated and unskilled migrant farm workers, it was a topical issue during the time of this study and was included in the research regardless.

The first popular moniker for Leamington, the Tomato Capital of Canada, comes from the combination of Essex County farmers' focus on tomatoes and the century-old presence of the 
H.J. Heinz Company in Leamington. Leamington, with its mild climate near the southernmost tip of Canada, and its proximity to the United States, is positioned as an ideal location for vegetable growers (Basok, 2002). In 1909, Leamington was chosen as the location for a major manufacturing plant by the H.J. Heinz Company, allowing bottles of Heinz ketchup to be proudly stamped with 'made in Canada' labels. Many local growers made their livelihood by selling their field tomatoes to Heinz (Wells, 2014). Tomatoes typically represent a small acreage of a growers' crop, but they are the most profitable vegetable for most southwestern Ontario growers (Atkins, 2013). However, in the fall of 2013, Heinz announced that it would be moving production to the United States. It marked the end of one hundred and five years of the relationship between Heinz and Leamington.

Employees, who mostly had been unionized and enjoyed a good wage, waited to hear what would happen to their jobs. A lack of outside interest threatened the futures of 800 full-time workers and 500 seasonal workers (Sale preventing closure, 2014). Then, Highbury Canco announced that by June $27^{\text {th }}$ they would be taking over operations at the plant (Sale preventing closure, 2014). Some news outlets reported that plant's volume is estimated to fall 60 percent and cause over 500 employees to lose their jobs (Wells, 2014). The owner of Highbury Canco, Surjit Babra, declared his intentions to make Essex County "Canada's food zone" and the "food processing centre of Ontario" (Vander Doelen, 2014).

The predominant focus of the media seemed to be on the imminent fallout following Heinz's departure. Journalists produced in-depth stories of local farmers' history with Heinz through multiple generations (Wells, 2014, Atkins, 2013, H.J. Heinz Co., 2014). The identity and historical association between Leamington and tomatoes was the focus of many stories. The fear for the future of employment was echoed even in local politics. During the lead-up to the 
provincial election of June 2014, local politicians' platforms emphasized employment and promised to work to attract major investors to the Chatham-Kent-Essex riding (Morrison, 2014).

News articles that have been published since Heinz made its big announcement in November have managed to paint a very clear picture of the delicate economy in Leamington. Both opinion pieces and standard articles serve to indicate that tomatoes and the livelihood of Essex County are very closely linked. Journalists appear to have capitalized on this theme, and as a result, Heinz and tomato production are portrayed as the backbone of Leamington in the vast majority of articles. The sentiment is explained by resident Dave Dick, "Heinz and Leamington are synonymous, and it's gone, you know?” (Wells 2014). The end of Heinz; however, does not mean the end of a vegetable-fueled economy in the region.

Leamington has also become the Greenhouse Capital of Canada. Basok (2002) describes the steady profits of growers who opted to produce vegetables year-round in greenhouses, and the industry has been very successful in Essex County. In 1999, there were 719 acres of greenhouses in Leamington, putting the town at the top of Ontario's greenhouse acreage (Basok, 2002). Essex County maintained the lead over the years and has continued to boom: today, 1,600 acres of greenhouses are concentrated in the region (Harrison, 2013). The scale of cucumber, tomato, bell pepper, and flower production in Leamington-area greenhouses is unparalleled.

It is easy to observe the culture of agriculture, including greenhouses and migrant workers, throughout Leamington. When driving along the southwestern portion of Highway 401 towards Windsor, wind turbines can be easier to spot than other people. It is not a very populated route, as massive farmlands seem to dominate the landscape. Once you exit the highway, however, to drive south towards Leamington, the surrounding fields transform into an overwhelming sight. Slowly, the unending farmers' fields start to become sporadically replaced 
by tall, modern greenhouses. Within closer proximity to the city limits, traditional fields become rare, as acres upon acres of greenhouses line the highways leading into Leamington. If you manage to see an open field, it is likely a site of construction for even more greenhouses. The sheer number of greenhouses is unlike any sight in other parts of Canada. The massive scale of the industry is evident, and the expansion on many properties indicates that it continues to grow.

The drive down Erie Street also shows signs of being influenced by visiting cultures from much further south. Corner stores and grocery marts post signs in their storefronts in English and also Spanish, advertising products like hot sauces, Jamaican patties, long distance calling cards, and other comforts from home to attract migrant workers. Tacos Tony's, owned by a MexicanCanadian, cooks up traditional Mexican fare and has become an incredibly popular restaurant for migrants and Canadians alike. There are nightclubs that boast Jamaican dancehall DJs and other cultural music fixtures. On both Thursday and Friday evenings, migrant workers take advantage of nights off from work and come into town to shop, run errands, and socialize. They even visibly outnumber the local permanent population on these evenings. The Uptown Leamington core bustles with several hundred workers, who ride their bikes, shop, and sit and socialize on the side of the road. It would indeed be an eye-opening experience for people living outside of migrant-receiving communities.

\section{Inequality, Invisibility, and Prejudice Faced by Migrant Workers}

The existing literature strongly enforces that migrant communities are segregated from greater society, in a variety of ways. The marginalization of migrant workers is most visible when they are placed in contrast against Canadians, specifically in terms of the limits to the rights and freedoms they enjoy as temporary workers. Researchers have analyzed the SAWP policy by looking at the reality it creates for migrant workers, especially in terms of tangible 
social experiences within Canadian society (Preibisch, 2004). I will first look at the inequalities associated with temporary migration. Next, I will examine the impacts of social marginalization, including racial stereotyping, prejudice, and invisibility.

\section{Temporary Migration and Inequality}

What factors lead to migrant workers' marginalization and precariousness? McLaughlin (2009) makes a strong case for the responsibility of neoliberalism in the power imbalances within the Seasonal Agricultural Workers Program. She argues that the power held by the Global North over the Global South is due to a history of postcolonial practices. Migrant workers are dependent on making their living from temporary labour in Canada because they lack of economic opportunity at home. The push factors of their migration are rooted in a history of oppression and control from the colonial past. Thus, the global division of labour causes enough desperation to create a vulnerable reserve army of labour that is disposable and easy to exploit. As a result of these influences, there is mutual dependency on a program where Canada's economy and industries are able to profit from the structural inequalities of globalization. Moreover, these structural inequalities have manifested themselves as social stratification.

The issues temporary migrants are suffering have a lot to do with their lack of citizenship status. Smith-Carrier and Bhuyan (2010) discuss the impact of neoliberalism on Canadian citizenship. They argue that the traditional social citizenship demarcates legal belonging, as well as access to social provisions such as employment insurance. However, what they identify as 'market citizenship' designates one's worthiness of full citizenship status by measuring their human capital (2010:4). Rights are not automatically granted; they are purchased by those who are capable of succeeding in the market. For instance, Canada has refused to sign the United Nations' document to protect the rights of migrant workers, arguing that federal laws offer sufficient protection (Flecker, 2011). However, when the Auditor General reviewed the TFWP in 
2009, she proclaimed it provided inadequate monitoring and enforcement of protective policies, creating an intensely vulnerable workforce (Flecker, 2011). An individual's skills and employability can thus impose boundaries on their belonging, inevitably creating a divide between those who earn permanency and those who are deemed to be permanently temporary. Those who directly contribute to the Canadian economy are no longer necessarily citizens. For instance, low-skill temporary foreign workers pay into social programs such as the Canadian Pension Plan and employment insurance, just like any other permanent resident. Despite their identical contributions to social benefits and the economy, many types of temporary workers are barred from ever accessing those benefits and attaining citizenship. Their value, in terms of human capital, prevents them from reaching the same status of belonging and citizenship as other immigrants and Canadians.

\section{The Impacts of Inequality}

According to the literature, legal-political parameters of 'Canadian-ness' are reflected in the social reality of migrant farm workers. The influence of legal-political barriers can be unpacked to examine social realities on a more micro scale. Seasonal agricultural workers are constructed as the other during their time in Canadian communities. Obstacles to reaching full participation in Canadian society are enacted in social interactions as well. There are interlocking systems of power and othering between workers and the rest of Canada. There is the potential for workers to experience power imbalances derived from social interactions, alongside the larger political drivers of belonging. In a study by McLaughlin (2009), workers are placed in a position to experience racial discrimination, class struggle, and urban over rural hierarchies as a result of their status in their temporary home. In analyzing the relationship between migrant workers and the settled community, barriers to belonging become evident through social isolation and segregation. The temporary worker's Canadian-ness can be said to be determined by the state as 
well as reinforced on a micro level. Workers' degree of belonging in Canada is varied and complex, but are undeniably enforced by the local community as well as the state.

There is extensive literature which analyzes the dynamics between migrant populations and local populations in both the United States and Canada. One primary theme which emerges from such studies is the considerations of symbolic boundaries between the two groups. Perry sees the SAWP as a relic of our racist and colonial past (2012:197). He argues that it allows the state to relegate the 'non-preferred' races to the margins of society while simultaneously broadcasting a reputation of multiculturalism. Colby (1997) compared workers' opinions of undocumented work in the United States to their jobs in Canada and found that 75 per cent experienced more racism and the majority felt more socially restricted in Canada. In one interview, a Hispanic worker attributed the higher prevalence of racism to the lack of Hispanic communities in rural Canada: "When we go out people stare at us. Maybe they think we're going to do something strange because we're different" (Colby, 1997:19). Preibisch (2004) also found that the whiteness of rural Ontario communities motivated growers to keep their employees housed on site, hiding them from the public eye. However, Basok (2002) found that workers appreciated the stability of a contract in Canada, and also found Canada to be reportedly less racist.

According to the literature, racial stereotyping is pervasive in communities that host temporary workers. Preibisch (2004) recognized the role of the community in shaping workers' social experience in Canada by describing them as gatekeepers to the community. Without context, some beliefs about Mexican or Jamaican workers' inherent tendencies are not harmful at first glance. However, stereotyping discounts workers' individuality and personal experiences; it devalues them as people and reduces their value to their perceived human capital. Across the 
literature, researchers noted that Mexican workers were believed to be loyal, hard-working, obedient, and unlikely to complain or protest about their work tasks (Hennebry, 2012, McLaughlin, 2009, Tomic et al., 2010). Comparatively, Jamaican and other Caribbean workers were viewed in opposition to these qualities. Growers were found to believe that Jamaican workers, due to the potential for connections to the Caribbean cultural centre in Toronto, were more likely to abandon their position, acted rowdier, and thanks to a lack of language barrier, were more likely to question their employer about safety concerns or other complaints (Hennebry, 2012, McLaughlin, 2009, Preibisch and Binford, 2007). For instance, one grower justified why he chose to employ Mexicans: "The Jamaicans are no good because they complain a lot, and spend their time partying" (Preibisch and Binford, 2007:21).

These racial stereotypes were found to be upheld by community members as well. Hennebry (2012) wrote that workers experienced harassment from community members, which she describes as coming from a place of fear or frustration with their presence in stores and "taking over our town" (2012:27). Leamington Mayor John Patterson found himself in hot water last year when he reached out to the police department for solutions to the city's alleged harassment problems, saying that his daughters and wife have been on the receiving end of troubling sexual comments at the hands of Jamaican workers (Sahoye, 2013). Part of the community reacted angrily, labelling his comments racist; while others suggested migrants get their own separate leisure areas in town (Watson, 2012). Justice for Migrant Workers (J4MW) wrote an open letter accusing the mayor of jumping to racialized stereotypes rather than dealing with the behaviour of some individuals (Open Letter, 2013). The tension between both groups is evident in the literature and media. Emphasizing the invisible and nearly unbreakable boundary 
separating the workers and the local community, Basok et al (2013) argue that this boundary results in problematic social isolation and tensions.

An internalized set of beliefs about the temporary workers was called 'garden variety' racism by Preibisch and Binford (2007), who argued that while the community usually did not display overt racism, they noted generalizations and racial stereotypes' prevalence with community members. Findings from a study by Hallet (2012) echoed this argument. He found that the surface-level amicability between the two groups was undermined by residents' “constant reiterations of inequality and the ethnic essentialism defining Latino migrants as 'suited for' the working conditions in poultry plants" (Hallet, 2012:104). Hallet (2012) and Preibisch and Binford (2007) show that there is a barrier to a meaningful relationship between residents and migrant workers due to the rural community's tendency to uphold racial stereotypes.

Prejudice is an important and common factor when analyzing local-migrant relationships. Preibisch and Binford (2007) found that a kind of unintentional yet underlying racism is commonly present among residents while discussing the behaviour of migrant workers. In an analysis of subtle prejudice versus blatant prejudice, Meertens and Pettigrew operated under the definition of prejudice as involving a perceived threat "combined with both formal and intimate rejection of the out-group"; however, they asserted that subtle prejudice involved a degree of covertness, where prejudice manifests in socially acceptable ways to reveal a bias (Meertens and Pettigrew, 1997:56). Burns and Gimpel (2000) researched public opinion towards immigration policy and became proponents for looking through a lens of prejudice when it comes to immigration issues. They paint prejudice in this context as " $[\ldots]$ ultimately an expression of selfinterested calculations based on one's economic position, and anti-immigration attitudes are 
traceable to economic anxieties" and argues that "it is the content of those stereotypes that matters in the determination of prejudice" (Burns and Gimpel, 2000:205,219). They found that residents' attitudes towards minority immigrants can easily become negative if they are influenced by unfavourable media reports. Another study of resident-migrant relations based in Europe found that friendships with individuals who belong to a minority group sway Europeans' attitudes away from hostile beliefs (McLaren, 2003). Social capital was brought into the discussion of migrant-local relations by Chavez et al (2006). Social capital gives value to the connections among individuals in terms of developing reciprocity and trustworthiness between groups. Burns and Gimpel (2000) and their findings are an interesting expansion to the friendship discovery by McLaren, as they argued that familiarity can breed contempt under certain circumstances. This is symbolic prejudice, where different cultures bring new behaviour that can be perceived to pose a threat to the permanent population's way of life (McLaren, 2003). It appears that migrants occupy a precarious status not only legally, but in the minds of residents whose opinions are swayed to allow for sweeping generalizations, ethnic essentialism, and racial stereotypes.

Why are ignorance and negative views held by residents towards migrant farm workers so prevalent in many studies? Frequently, researchers point to a lack of social interaction between the two groups to explain the poor relationship. There is simply an omnipresent social barrier between the two groups, according to research. One common explanation for limited social inclusion is found within the policy of the program. Several researchers linked social exclusion to restrictions inherent to the SAWP. The structure of the SAWP, which recruits poor applicants, has workers straining to work as many hours as possible for overtime money (McLaughlin, 2009). Therefore, workers are indirectly avoiding leisure time and are not 
spending their hard-earned money on socializing (Preibisch, 2002). Furthermore, the SAWP gives individual employers the power to dismiss their workers on a whim without repercussions. Workers' behaviour is therefore controlled by the fear of repatriation (Preibisch, 2002). Those who desire to return annually to work under contract as a 'named' worker must supress complaints, radical behaviour, and avoid conflicts to avoid being replaced (Preibisch and Binford 2007). Thus, their power to combat unjust situations during their stay in Canadian communities is severely restricted. The power given to the growers provokes migrant workers to simply keep their heads down to avoid any misstep that could cost them their job. Finally, the SAWP provides no official language training for Spanish-speaking Mexican workers, which completely limits their ability to interact meaningfully with the Canadian community (Griffith, 2013).

Basok (2002) interviewed Mexican workers employed by growers in Leamington. She found that "there is very little social life for Mexicans in Canada" (2002:123). The fear of being reprimanded by their boss caused workers to cut nights at the bar short, for instance. She found that the most significant social get-togethers with fellow workers occurred outside of supermarkets on Thursday and Friday nights. The social significance of the weekly shopping trips into town is also documented by Preibisch (2004) and Read et al. (2013). Not only do workers enjoy social interaction within their own group on nights off for running errands, it is also the time when workers interact with locals in the community. Interaction during errand trips was found to be superficial, as interactions with store clerks are hardly the opportunity to connect on a meaningful level (Read et al., 2013). Workers also described interactions with Canadians as overtly negative, reporting that citizens treat them with little respect on days when they went to town to shop. Employees did not respond to their greetings, gave them dirty looks, or treated them like they were stupid (Preibisch, 2004). It is evident that racial stereotyping is pervasive 
through the community of residents and growers. The literature asserts that stereotyping has led, at its worst, to overt discrimination. At best, these ingrained beliefs have deteriorated the quality of the brief social interaction that both Mexican and Caribbean workers experience during visits to the rural community.

\section{Research Methodology}

The research was motivated by the desire to determine the place that migrant workers hold in Canadian society. The research question asked how Leamington residents envisioned the impact of foreign migrant workers on their community. The question also served to uncover the level of interactions between the members of the community and migrant workers, as well as their perceptions and attitudes towards them. What are migrant workers' roles and impacts within their temporary Canadian home, as viewed by community members? To answer these questions, the experiences of locals who live in Leamington, which supports the Seasonal Agricultural Workers Program, are intrinsically valuable. The aim of the project is to gain a clearer understanding of local community members' attitudes and awareness levels of the migrant farm workers in their region.

\section{$\underline{\text { Design }}$}

A mixed method descriptive research design was used to explore the attitudes of Leamington residents towards migrant farm workers living in their community. The mixed methods involved reviewing historical archival data and newspaper stories as well as conducting surveys and interviews.

\section{Target Population}

The town of Leamington, known as the Tomato Capital of Ontario, was selected as the location for the study. Leamington has had a long and prolific agricultural economy. It has had 
the longest experience with the SAWP and is considered to have one of the largest seasonal farm worker populations living within the city and the surrounding Essex County. Recent news stories involving complaints about the attitudes of the migrant farm workers by some members of the community also made this town an attractive place for this project.

News stories about the recent closing of the Heinz manufacturing plant, as well as complaints regarding migrant farm workers, have been considered to gain insight into the tensions between local residents and migrant farm workers and whether economic decline would have any impact on these tensions. The inclusion criteria included 1) current or former residents of Leamington, 2) Being 19 years of age or older and 3) being a permanent resident or a Canadian citizen.

\section{Sample}

A convenience sample of 11 people was recruited from various community settings and through snowball sampling. Having undertaken this study without any personal connections to the town of Leamington, the recruitment process involved 'cold-calling' various businesses and organizations to ask if they would be willing to post the study's recruitment flyer. Establishments including the local bingo hall and the public library were asked, as well as the administrator of a Facebook group called Leamington Stand Strong (LSS). LSS, with thousands of followers, was created in response to the announcement that Heinz would be pulling out of Leamington and moving to the U.S. The library and LSS agreed to share my flyer.

Initially I was planning to ask 20 members of the local community to fill out the surveys. As there was a tight timeline for data collection, a total of 16 people responded to the flyer. Of those 16 replies, 11 filled out surveys and two of those 11 respondents also participated in interviews. I intended to ask five people to participate in follow-up interviews to the survey. The interviews were an opportunity to collect qualitative data about unforeseen topics, guided by the 
participant. Because this study was exploratory, it was ideal to gain ideas for future direction of questions, topics, and issues to address from the participants through the interview. The interviews created the opportunity for participants to bring up personal experiences and other stories that questions did not directly address in the survey.

\section{Ethical Considerations}

The only foreseen risk associated with participation in the study was the potential to be asked to share personal opinions that might be construed by some as controversial or offensive. Measures were taken to prevent participants' names from being attached to controversial statements. Participants were given pseudonyms for the study. Throughout this paper, the participants' names are changed to ensure confidentiality. Participants were informed of their rights to confidentiality while signing the study's consent form, and they were also told about their right to withdraw their contributions at any time from the study.

\section{$\underline{\text { Data Collection }}$}

The data was collected during face-to-face interviews in some instances, and in some cases through email correspondence. Those interested in the study were contacted to assess eligibility, obtain consent, and if appropriate, arrange a convenient time and place to meet for the survey and/or interview. Data collection involved responding to a survey questionnaire which took approximately one hour to complete. The survey consisted of 22 questions which included both closed and open-ended questions (See Appendix B). The open-ended questions were included throughout the survey to encourage participants to share and elaborate lengthily about their opinions. The nature of this study was an exploratory project meant to serve as the first step to more in-depth research on the topic. There is yet to be a significant quantity of data in the existing literature. Therefore, qualitative methods such as open-ended survey questions and 
interviews provided the opportunity to collect insight to guide further research. Participants' responses to open-ended questions were recorded verbatim.

\section{Data Analysis}

The analysis of the findings was based on both the qualitative and quantitative data. Survey questions that asked how often participants had interactions with migrant workers, for instance, as well as Likert scales were included to represent ordinal values. In order to analyze the data, measurements were used to operationalize the quantitative data that was collected. The quantitative data was investigated using descriptive analysis, including measuring proportion and frequencies of response options. Spreadsheets were created in the Excel program to facilitate analysis. Sample quotations from the two interviews, as well as written responses to the openended survey questions, were selected to examine questions regarding attitudes toward the necessity of migrant farm labour, contact with the farm workers, familiarity with the working and living conditions of farm workers and attitudes and prejudices towards farm workers.

\section{Findings}

The people from the local population who opted to respond to the recruitment flyer had strong opinions about the migrant farm workers' presence in their town. Overall, they were quite eager to share their observations with me, which indicated that the research had struck upon a hot button issue. Indeed, the presence of a few thousand migrant workers had become a contentious issue within the media, for town council, for the police force, and for the Leamington residents as well. While migrant farm workers face obscurity from the public eye in other places, the issues involved with their presence has not been swept under the rug for Leamingtonians. Most of the respondents held very different, yet very strong, opinions towards the unique convergence of the two groups of temporary workers and permanent residents. While the respondents came 
from diverse backgrounds and degrees of involvement with migrant farm workers, they were similar in their willingness to share their experiences towards bettering their place of residence. The data collected reflected the complexity of the viewpoints of each individual participant. Differing viewpoints held by different individuals can be attributed to a number of factors. Their personal experiences can be enriched by understanding what factors shape and influence their social experiences. In compiling the data from questionnaire responses, certain themes and common opinions emerged. In order to incorporate the participants' backgrounds into the analysis of their responses, basic demographic data were collected (See Appendix C). All participants were over 30 years of age, and the age categories of 41-50 and 61-70 were the most common, at three participants each. All but one participant had attended a post-secondary institution, and the vast majority held university bachelor's degrees. Two participants reported being born outside of Canada and they both had status as landed immigrants at one point in their lives. The rest were Canadian citizens.

Participants' employment background also had potential for alluding to the experiences behind their attitudes towards migrant farm workers. Two individuals had volunteered time with migrant-serving organizations, including a bicycle safety program and a health initiative. Their knowledge of the SAWP was clearly more acute than others who were more loosely connected to the migrant community. The latter group included a former bartender who was familiar with alcohol-fueled interactions between migrant men and Canadian patrons, and a retired food industry worker who, frustrated by a low number of farm workers, had frequently petitioned for changes to provincial labour practices. Another participant was a retired engineer who remembered the realities of growing up on a farm before the availability of foreign labour. A store owner's business was situated just outside of the problematic Uptown Leamington core. 
Others were even farther removed from job-related associations with migrant workers, including office workers such an accountant, IT professional, and an administrator.

The survey included questions that asked about the frequency of social contact between the migrant workers and local population. Firstly, participants were asked how often they saw migrant farm workers during the summer. The vast majority of those surveyed reported daily sightings. Only one person reported seeing workers less frequently, at once per week. The survey also asked how often migrant workers were seen by participants in the winter. All respondents except for the former residents reported that they still saw workers at least a few times per month in the winter months. Taking a different angle, the participants were then asked to report how often they interacted with migrant farm workers, whether this was through conversations, client interactions at their place of work, or community events. While the majority of participants did report remarkably frequent sightings of migrant workers, the amount of meaningful interaction was far more limited. The most common frequency of interaction was 'rarely', and most participants aligned themselves at the lower end of the range of social interaction. Thus, the participants who cited interacting with workers in a conversational sense were far less numerous than expected, considering the regularity of daily sightings of migrant workers. It did not appear that residents were having frequent social interactions with migrant workers.

One question on the Likert scale aimed to measure respondents' reaction to the statement "local growers need to hire foreign workers to ensure they had an adequately large workforce for seasonal farm work". The responses were particularly divided here. Eight participants reported agreeing or strongly agreeing with the statement, while three disagreed or strongly disagreed. People who agreed with the need for migrant farm workers argued that local residents would not 
make up an adequate or reliable workforce, while those who disagreed believed that the local unemployed population should be filling the job openings for farm work instead.

Participants were then asked to place themselves on an identical Likert Scale in response to the statement "I consider myself to be knowledgeable of the following details of the Seasonal Agricultural Workers Program." The details included work hours, job tasks, housing, and worker rights. Overall, participants considered themselves to be fairly knowledgeable on the experiences migrants have within the SAWP. None of the participants claimed to be completely knowledgeable about workers' rights and this appeared to be the haziest detail of the program. Participants were most comfortable with their knowledge of the programs' job tasks. Notably, many participants chose to identify themselves as 'neutral' in response to work hours, housing, and workers' rights.

Participants were asked to list their attitude towards the future of employment in Leamington, considering the recent departure of Heinz, on a scale from 'extremely positive' to 'extremely negative'. Half of respondents reported having positive outlooks, while the other half reported being negative about the future of employment. Respondents were also asked if they thought the public opinion towards temporary foreign workers would change considering the sale of Heinz in Leamington. The follow-up question elicited a strong negative response, with seven people answering 'no'. Four people were unsure.

In order to gage the public's views of inclusiveness, participants were asked their stance on the statement "I believe my community should do more to include migrant farm workers in the Leamington community." Interestingly, most participants aligned themselves as 'neutral' towards the statement, while nobody disagreed with the statement. Participants were overall more likely to have witnessed or heard of stories of troubling treatment of community members 
by migrant workers than migrant workers by community members, or migrant workers at the hands of their employers.

\section{Analysis}

Some questions of the survey were open-ended and allowed for participants to elaborate on their responses. The qualitative responses aided in analyzing the data, as the added detail explained the motivation behind some answers. The findings provided significant insight into the reality of Leamington. Leamington, in existing literature, is depicted as a place with unparalleled levels of visibility and familiarity between the citizens and temporary workers. The first major theme that was extracted from the data was the overarching belief that migrant workers are necessary for the continued success of Leamington's economy. The second theme involved the quality of social interactions between migrant workers and community members. Through analyzing conversations and surveys it became clear that increased familiarity with migrant workers does not necessarily breed meaningful social interaction. The third theme, and the largest portion of this study's analysis, discusses the implications of a lack of meaningful social interaction.

\section{The Necessity of Farm Workers}

People from Leamington held strong beliefs toward the need for migrant farm workers. They did not identify with the same belief across the board, but it seems that as only one person remained neutral that this is an issue that people have seriously considered. While we cannot say that the public opinion collectively agrees that migrants are either intrinsic or inessential to growers' success, the public certainly has strong opinions. 
Initially, the idea that participants' age might have been a significant factor for who supports the SAWP's existence was considered. Older residents were likely to recall the way things worked in Leamington before the ubiquitous use of migrant labour, when students used to be hired to pick during the summers. Upon further analysis, there was no connection found between older participants and a negative stance towards the SAWP. While the oldest participant, over the age of 70, was opposed to the idea that migrant workers are essential to growers' success, the only other age group which also voiced opposition was the 41-50 year olds. There was no evidence in this sample to show that age influenced stance towards the existence of the SAWP. However, the youngest age groups were underrepresented in the survey, so further research could reveal a relationship between age and adherence to the SAWP.

Among those who disagree with the existence or pervasiveness of the migrant labour practice, there seemed to be predominant train of thought. These respondents' reasoning involved grouping the SAWP's workers together with low-skilled and unemployed Canadians. An older respondent named James elaborated that with the cost of airfare and other added expenses on top of minimum wage paid to migrant workers, that he believed the true cost of foreign labour is very close to a wage that could entice the local unemployed population to join the agricultural workforce. As a senior in the community, he recalled that he and many others did the same work in their early years. "If the work is so unsuitable for todays' generation, then my taxes are unsuitable to sympathize," James said in regard to people who choose to live on Employment Insurance (EI) rather than take a job in the fields or greenhouses. Another participant who disagreed with the SAWP felt that growers should hire from the pool of unemployed locals prior to outsourcing the labour to offshore labourers. Thus, it can be said that those who disagree with the use of foreign labour tend to conceptualize migrant workers as a 
direct replacement for the unemployed population. SAWP naysayers appear to also take issue with those who are unemployed and living off social assistance. People who adhere to this vein of reason see the unemployed population as the solution to the labour shortage instead of bringing the SAWP into existence.

Those who are in support of the program take a pragmatic stance toward the cost of labour and the unwillingness of local residents to do the work. This line of reasoning, which supports the existence of the SAWP, was by far the most common. One participant mentioned that there were far fewer greenhouses thirty or more years ago, so students were able to make up the labour supply during their summer breaks alongside Mexican Mennonite workers. Julian, who grew up on his immigrant parents' farm in the 1950s, explained that even when students were willing to do the work, they were entirely unreliable and would quit as soon as they had enough money for beer or their cars. The unreliable labour resulted in a major lack of profits: "I saw my dad distraught many times because he had to plow under fields of perfectly good produce because we could not get people to pick the tomatoes and cukes." Thus, it appears that most of the public recognizes the migrant farm workers as a permanent and key fixture in the local economy. Students and other people struggling to find employment are not adequate for the agricultural industry. A participant named Joshua argued that local workers will always quit as soon as something better comes along, and that "this is totally understandable. Everyone wants to improve their lives and Canadians have other opportunities which are unavailable to the seasonal migrants." Melissa explained her sense of the general public opinion of migrant farm workers. She pointed out that most people in her experience recognize them as important contributors to the success of the greenhouse industry, which is now poised as the next major industry after the departure of Heinz. "Most people recognize that these hard-working people are doing jobs that 
very few local residents are willing to do," Melissa clarified. Another participant wrote, "I don't believe the workforce in Leamington is willing to do the work and work in conditions that those foreign workers do." It can be said that amongst those who believe in the program, there is a general consensus that the migrant farm workers are not only helping the growers, but playing a massive role in supporting the local economy. The growers are benefitting from their committed labour, and so is Essex County as a whole, especially considering that Heinz has just departed and there is a need for the greenhouse industry to step in and take its place.

It appears that the media-generated fear of the town's collapse following the departure of Heinz was not shared by all participants. Responding to a question regarding the future of regular, non-temporary employment in Leamington, respondents were evenly split between positive and negative outlooks. Not everyone in the town is fearful of an economic downturn. There were hopeful mentions of the booming greenhouse industry stepping in as the number one industry and of Highbury Canco taking over Heinz's manufacturing plant.

Furthermore, the fallout from employment changes did not appear to be sparking any animosity towards the migrant farm workers. The 'migrant workers are stealing our jobs' mentality was not at all present in the data collected. In fact, participants appeared to see the dilemma of Heinz workers and migrant farm workers as entirely separate issues. Former Heinz employees who were about to be laid off were not seen as the same type of worker as migrant labourers working on farms. Megan explained it succinctly: “I don't believe public opinion [toward migrants] will change even with increased unemployment because the positions filled by foreign workers are much lower paying and less specialized positions, which again, I feel the workforce of Leamington is unwilling to fill." Joshua saw migrant workers as key participants in the stimulation of both the private and public sector, arguing that they help Canadian agricultural 
companies compete in the global market which in turn creates jobs across many industries. He wrote,

“It's a win-win-win. A win for Canada's food industry. A win for Canadian workers who'd be jobless if these companies relocated - as Heinz did. And a win for the foreigner workers - who return to their homes and families after the season to where their savings afford them a much higher standard of living than average."

As was previously discussed, the handful of residents who disagreed with the use of migrant workers held that viewpoint because they believed growers should primarily be hiring local unemployed people on social assistance. However, it seems that the former Heinz employees were seen by many participants as high-skilled and specialized labourers. One participant explained that migrant workers are not perceived as a threat to other employment in Leamington.

\section{Limited Contact between Locals and Migrants}

Another significant finding of the data comes from the idea of visibility. Existing literature had made it evident that Leamington was a site where migrant farm workers enjoy relative visibility during their stay in Canada (Basok, 2000; Basok and Binford, 2004; McLaughlin, 2009). This was found to be true, on the surface level, in Leamington. Through analyzing the data, it was clear that nearly every resident of the Leamington area came across migrant workers daily during the summer, the primary growing season. Even in the winter, more than three-quarters of residents surveyed reported seeing migrants more than once a month. The level of year-round visibility for migrant farm workers is likely unprecedented compared to the rest of the province and even the country. However, this finding calls for additional analysis. Yes, migrant workers have a distinct presence in Leamington. But how does this visibility impact their lives and the lives of community members? The idea of visibility must be unpacked further. 
It is important to note that visibility is not necessarily accompanied by meaningful social interactions, inclusiveness, friendship, or even a sense of welcoming.

The findings reflect the need to distinguish between 'visibility' and social interaction. While every current resident who was included in the study reported seeing migrant workers remarkably frequently, a much lower number of people reported actually interacting with migrant workers. If residents are not actively communicating or interacting with migrant farm workers in social situations, it begs the question of how the residents even know that they are indeed foreign labourers rather than community members. One possible explanation is that Leamington, being a predominately White rural town, leaves racialized workers coming from Mexico and Jamaica to stand out from the permanent population. Lack of diversity in Leamington, unlike bigger and more cosmopolitan urban areas, allows ethnic and racial tensions to be even more pronounced. In any case, the assumption on the part of residents reveals a significant disconnection between the two different communities. The familiarity seems to be built solely on a passing recognisability rather than meaningful social interactions.

Another barrier to effective interaction between workers and local residents was that locals had only limited knowledge of the SAWP's policies or tendencies regarding work hours, worker rights, and housing. While most people I interviewed indicated that they were generally familiar with the tasks of farm labourers and frequently see them in town, they lacked a clear understanding of their living and working conditions. Likewise, workers also had little idea about the community norms and customs, according to some participants. If anything, it is further evidence that there is a barrier between both communities.

Of course, language barriers are a possible deterrent to meaningful interactions, and every casual conversation at the grocery store probably does not explore the ins and outs of farm work. 
However, the outer community could gather information about the realities of the SAWP through the media, or through public programs instead of relying on local gossip and hearsay. As participant John said, "Everybody in Leamington has a friend or a friend of a friend who is a grower." While direct interactions between the two communities are unlikely to involve long conversations about the downsides of crowded housing arrangements, or otherwise, it is still surprising that the participants' self-professed knowledge about the program is somewhat lacking. While the agricultural industry is a comfortable part of everyday life in Essex County, the experiences of migrant farm workers are not at the forefront of most residents' minds.

The lack of attention towards migrant farm workers reveals a hierarchy of importance of different groups in the community. To support this argument, compare the awareness of the SAWP to the town's preoccupation with the departure of Heinz. From the data, it is evident that there is a collective knowledge, concern, and awareness of the impending employment changes for former Heinz workers. Participants were confident in their knowledge of the situation at Heinz. They cited layoff predictions, explained that most Heinz employees had held their jobs for many years, discussed their relatively high wages, and the fact that most had been unionized. The predicament has been well-covered in the local newspapers, and the community is collectively rallying for the continued survival of Leamington. The annual Tomato Festival proceeded without fail this year. A popular Facebook group called Leamington Stand Strong came into existence following Heinz's announcement in November 2013. The group has over three thousand followers and it focuses on supporting local businesses and spreading the word about community events. Thus, it can be said that it appears the community is imbalanced in its knowledge and attention towards two major industries in its town. The data revealed that the SAWP does not attract as much attention from residents in the same way that other local issues 
do. The community's inattention to the migrant workers' experiences indicates migrants' lack of complete belonging to the Leamington community. Migrant workers are not high on the ladder of the public's interest, meaning they are others in the community.

The limited contact between residents and migrant workers indisputably results in a very low level of meaningful social interaction. Despite the fact that Leamington area residents recognize the intrinsically important role that migrant farm workers play in the local economy, their familiarity and respect for workers does not translate into a strong relationship between the groups. The participants in this study painted a picture of a new type of invisibility, one where migrant workers are a prominent feature on Essex County's physical landscape and yet they remain essentially invisible on the social landscape.

\section{The Implications of Social Invisibility}

One participant wished to discuss the aim of the project, as she was concerned about the amount of negative press that the Temporary Foreign Workers Program had received as of late in the national media. She acknowledged that migrant worker programs are a complex topic, but wanted to clarify that Leamington recognizes the positive contributions of migrant workers in making the town more diverse and economically strong. The data revealed that while residents do recognize the importance of migrant workers, there are still barriers to better social inclusion. There is no doubt that migrant workers have impacted the town of Leamington in a variety of ways. Changes have taken place in Leamington as a direct result of the presence of migrant workers. Residents interpret their impact in a variety of ways; as it is indeed a complex situation. There were two main themes which were important to extract from the data. The first involved discussion of the transformation of the Uptown Leamington neighborhood. The other was racial stereotyping. 


\section{Uptown Leamington}

One recurring issue that was mentioned by participants throughout the data was the transformation of 'Uptown Leamington', a neighborhood that was formerly known as the downtown core around the intersection of Talbot Street and Erie Street. The general environment of this neighborhood has reportedly changed dramatically in recent years. Whereas the centre of Leamington for shopping, nightlife, and other social activities was once considered Talbot and Erie, today it has migrated closer to the waterfront. This issue was at the forefront of many residents' minds, as the public has become wary of the area recently. One participant described the changes, saying that Uptown Leamington now caters to migrants, as there are bars specifically known as migrant worker hang-outs, convenience stores and restaurants that sell ethnic foods, and Western Union-style banks for migrant workers to easily send remittances home. Significant portions of the area's housing have been converted into rental homes for migrants during the growing season. During interviews, participants emphasized that there is not a lot of mixing between workers' bars and residents' bars. In fact, police caution residents to avoid the neighborhood at night. The participants' stories about the segregation of the downtown districts are practically reminiscent of historical Black segregation in the United States. One participant said when his sister continued to jog through the neighborhood at night; he and others called her crazy and tried to persuade her to stop. He acknowledged that the drug problem of the area is not solely blamed on migrant workers, but also local dealers.

Roberta was concerned with her and her family's safety, seeing as they lived in Uptown Leamington. She elaborated on the root of the residents' reluctance to frequent the area. She cited verbal and physical sexual harassment as a deterrent for women. Her levels of frustration were so extreme that she began bringing her dog on runs to protect herself from migrant men approaching her. Catcalls were common, and oftentimes workers approached her 
inappropriately. She described the workers as more boisterous and bolder than typical Canadian men. Residents became more aware of the prevalence of the harassment when the mayor's teenage daughter reported being shaken up after an encounter with a Jamaican worker. It was written about in the local paper, and the mayor called for the community to address the cultural clash. While some residents agreed with the mayor, other residents reacted negatively, as they saw the move as harmful stereotyping of Jamaican workers. The Jamaican Counsel was brought in to help resolve the situation.

No matter your viewpoint, it is undeniable that Uptown Leamington has been transformed to serve the minority Mexican and Caribbean population. Driving through town, the evidence is easy to see. Tony's Tacos is a fixture on Erie Street. It is a small restaurant that serves Mexican fare, and not only to Mexican workers either. Many convenience stores boast Jamaican patties and hot sauces from signs on their windows. A nightclub just off the main strip advertises a Thursday night dancehall DJ. Store owners are familiar with the Thursday and Friday night presence of migrant workers, who line the curbs and hang out in big groups outside grocery stores, banks, and the one remaining payphone in Uptown Leamington. Some participants discussed how friends of theirs - especially women - had changed their shopping habits, and would do their errands on other nights of the week.

One participant argued the other side of the issue, saying that Uptown Leamington was faltering before the migrant workers arrived, as many local residents were not supporting the local economy and were doing their shopping elsewhere. Another participant agreed, saying that she believed that Uptown Leamington was lucky to be saved by the revitalization spurred on by the migrants' presence.

\section{Racial Stereotyping}


Another theme that emerged from the data, especially in reaction to the way the town is overwhelmed by migrant workers on their nights off at the end of the work week, is racial stereotyping. As Roberta puts it, "I never used to think about these things, but living in Leamington has made me more intolerant and I don't like it." Throughout the survey and interviews, participants were not communicating overtly intolerant or racist opinions. Even those who disagreed with the SAWP certainly did not defend their beliefs with xenophobic statements. However, there were frequent indications that participants of the study held internalized beliefs about Mexican and Caribbean workers, including ethnic essentialisms and racial stereotypes. Preibisch and Hennebry (2007) found that participants of their study showed signs of what they called 'garden variety' racism rather than overt racism. Their finding can be applied to this study as well, regarding participants who shared their views of certain migrant groups.

While discussing whether participants had witnessed or heard of any troubling behaviour between migrant workers, their employers, and the community, harassment was frequently noted. Even if the participants had not personally experienced harassment, they could quickly think of several stories they had heard from primarily female friends and family. These experiences appeared to shape the residents' view towards the different nationalities of migrants. Participants tended to associate certain behaviour with the Mexican workers and other behaviour with Caribbean workers. It is important to note that participants were mostly apologetic while giving accounts of their experiences with migrant men in town. Many participants acknowledged that they did not intend to come across as racist, or that they realized their statements could come across badly, prior to telling their stories about negative experiences involving Caribbean men. They were aware of their potentially harmful internalized opinions regarding certain nationalities 
of migrant workers. This is another instance where Preibisch and Hennebry's 'garden variety' racism theory holds ground (2007).

Often, participants specified that it was Jamaicans who were behaving less than favourably towards the local women while socializing outside of stores. There were no reports of Mexican workers acting inappropriately. In fact, many participants clarified their different experiences with both nationalities. Mexicans were often described as polite, friendly, and open to greetings from locals passing on the sidewalk. Jamaicans were associated with catcalling and other harassing behavior. One participant said that his wife had been followed to her car one day by Jamaican workers, and she changed her shopping habits. Jamaicans were also portrayed as less likely to respond to greetings or chat with Canadians. It is possible that this perceived behavioural difference is related to language differences. While Mexican workers are typically unable to speak English, most Jamaicans' mother tongue is English (Garcia-Colon and Melendez, 2013; Griffith, 2013). It is possible that Mexican workers may only know basic English greetings, and thus are perceived as more polite than Jamaican workers, who are not at all limited by language barriers. This could be where the 'polite versus boisterous' reputation emerges.

On the other hand, it is important to note that while the racial stereotyping was prevalent in the data, none of the participants conveyed xenophobic beliefs. In fact, some participants clarified their stances on the sensitive issues by acknowledging that different cultures have different norms, indicating they believed that a culture clash was at the source of these tensions. Julian, after explaining his experiences with both nationalities, justified his story. "Different cultures, different experiences with locals, perhaps." Another participant argued that while some residents are uncomfortable being in town on nights when migrants are gathering to socialize and 
do their errands, it is simply a cultural difference. While Leamington residents think of the social gatherings as loitering, the participant described it as a part of their custom to gather in the town centre. Participants seem to be in agreement that the clashes between the community and the migrant workers could be attributed to cultural differences. Some suggested that workers should be made aware of what is acceptable in Canadian culture while they are present in our country, pushing education or cultural sensitivity as the answer to the cultural clashes. As business owner Martha pointed out, "I'm not opposed to these migrant workers, any culture, being in our town but they need to be educated in our culture, the way we would have to accept theirs in their countries." It seemed that the public opinion was in agreement that in order to protect everyone, from harassment, from bicycle accidents, and cultural clashes, that a little more cross-cultural education could benefit both populations.

\section{Conclusion}

The literature finds that Canadians are largely unaware of the contributions of migrant farm workers to Canadian agricultural as well as their living and working conditions and marginalized status (Chavez et al, 2006; McLaughlin, 2009). This exploratory project, while small in scale, was undertaken in order to add insights on the social marginalization and invisibility of migrant workers from the perspective of a community who could actually physically see them. The project explored the opinions of a small sample of Leamington residents who are not actively engaged in farming, in terms of their perceptions of both the role and the impact of migrant farm workers in their community. Participants' accounts of everyday experiences around the community were collected through surveys and interviews. There was much knowledge to be gained from the analysis of social interactions. Social experiences in 
Leamington between the permanent and the temporary population served to shine a light on the barriers migrants face to inclusion in the community.

Much of the existing research focuses on the legal and political issues surrounding the SAWP at a federal policy level (Brem, 2006; Chaccon, 2011). In compiling research on the topic of seasonal agricultural workers, one aspect has been primarily overlooked. Precariousness can be a result of legal-political regulations, but precarious status can be directly influenced by the repercussions of social marginalization. Existing research has argued that migrant workers' experiences in their host communities improve when they are incorporated into the fabric of the community, including through social participation, friendships, health care or settlement services (McLaren, 2003; McLaughlin, 2009; Preibisch and Binford, 2007). This study aimed to uncover issues and gain an understanding of the reality of migrants' everyday life in Leamington at a tangible level by giving attention to social interactions.

There were three primary findings that were extracted from the data that was collected. Firstly, it was found that the majority of local residents believe in the inevitability and necessity of the migrant workers, and their role in furthering the local economy. The 'temporary workers steal our jobs' attitude was completely absent from the minds of the participants in this study, as some clarified that local residents would never do the work that migrant farm workers are willing to perform. Despite massive overhauls to the region's employment, through the departure of Heinz, many participants clarified that migrant workers were never seen as a threat to the local workforce, as the tasks, skills, and wages were on two very different levels. The departure of Heinz did not influence the participants' attitudes towards the program.

However, the belief in the necessity of migrant workers' presence did not lead to a deeper understanding of their conditions of living and working, nor closer relations between the 
permanent and temporary residents. The second major finding revealed that the contact between workers and community members was found to be predominantly superficial. While most participants reported that they saw migrant workers daily, their reports of less frequent social interactions indicated a fairly shallow social relationship.

Lastly, the low social interaction level was related to the social marginalization of migrant workers. Social marginalization was evident in participants' reports of community attitudes towards the Uptown Leamington neighbourhood. The tendency for migrant workers to use this neighborhood for errands and socializing reportedly caused residents to become wary of the area, which adopted a reputation for being unsafe at night. Furthermore, social marginalization became tangible through participants' reports of harassment. The behaviour of migrant workers was often essentialized and assigned to either Mexican or Caribbean workers. Racial stereotyping manifested from the data in the form of internalized sets of beliefs that participants held about the differences between workers coming from Mexico and the Caribbean. Social invisibility, racial stereotyping, and culture clash were linked to a lack of meaningful social relationships.

\section{Limitations}

This project adopted a new perspective on the topic of migrant worker issues, by approaching the topic from the viewpoint of community members. Thus, there were not any adequately similar studies to use as a jump-off point for the structure and content of the survey questions. This lack of background structure may have caused missed opportunities with the type of questions that were asked in the survey. The questions were unique to this study. Due to time constraints, it was not possible to conduct a pilot study to test the survey questions prior to engaging participants. Unfortunately, the type and amount of data collected was not sufficient to 
draw any meaningful conclusions that would have statistical significance. This was especially the case when it came to gender differences in the participant responses. It was also difficult to demonstrate that historical agricultural trends across Canada applied to Essex County as well. It would have been ideal to provide demographic statistics from census data that proved a trend of rural depopulation in the area; however, the data that was found was not able to illustrate the population trend.

The only foreseen risk associated with participation in the study was the potential to be asked to share personal opinions that might be construed by some as controversial or offensive. Thus, a social desirability bias had to be taken into account in the analysis of the data. To reiterate, the literature was saturated with examples of racial stereotyping and 'garden variety' racism (Hennebry, 2012; McLaughlin, 2009; Preibisch and Binford, 2007). Social desirability bias describes the propensity of participants to give the 'ideal' answer, or downplay what they perceive to be undesirable answers when faced with sensitive topics during studies (Chung and Monroe, 2003). This bias was likely to be present in this project, due to the amount of questions regarding the attitudes towards and behaviour of a visible minority group in a predominantly white town. Social desirability bias is a potential limitation on the quality of the data that was collected for the study.

\section{Policy Recommendations}

Steps to building a safer and more harmonious community can be initiated at the local micro level. Some participants argued that abrasive social interactions between residents and the community could be blamed on a lack of cross-cultural education. Due to the apparent impact of

culture clash, this assertion is worth considering to improve the quality of social interactions. The Jamaican Consulate admitted they did not train workers about etiquette and social behaviour in Canada (Sahoye, 2013). A crash course for migrant workers before entering the foreign country 
that involves learning about customs, greetings, and appropriate behaviour would be a simple and useful way to improve Leamington's social environment. Likewise, having community members become more welcoming to the migrant community is equally important. Public awareness campaigns should be implemented for community members to educate themselves about migrant farm workers.

Black (2013) reported that to tackle the issue, the police recommended the Leamington Council pass an anti-loitering regulation to deter people from congregating outside stores in the Uptown Leamington core. However, this is reactive policy rather than proactive policy. To stop negative interactions between workers and locals, especially those that have been blamed on cultural and racial differences, policy changes must focus on improving the relationship between the two groups. To do so, Leamington residents must grow to accept migrant workers as a part of their community, rather than temporary visitors. Community events, political decisions, settlement services, and other welcoming behaviour should incorporate migrant workers to spark the opportunity for social participation and meaningful social interactions between the two groups. Examples of such actions would include communal sports leagues, or a community centre with designated hang-out spaces for workers to give them a place to be social. Another possibility would be to provide free conversational English tutorials for Spanish workers, by setting up a volunteer system with local high school students to complete their mandatory 40 hours of volunteering. This policy suggestion would serve two purposes: to get the younger generations involved with the migrant worker population on a meaningful level, and to ease Mexican workers' ability to engage, converse, and interact with the local residents.

\section{Future Research}


There were some loose ends that this project was not equipped to follow up on, due to time constraints and limited resources. There were several parts of this study that proved fascinating and had the potential to add value to the research. In a future version of this study, there are numerous aspects that could be revisited with greater detail. For instance, the pool of participants should be broadened. Younger participants, under the age of 40, were severely underrepresented. There would likely be valuable data regarding the differences of opinions held by people of different age categories. It would also have been extremely valuable to approach political and other community leaders in order to interview them about their perspective on the aforementioned issues between the temporary and the permanent residents in their community. Interviewing members of the police force about community violence, asking members of city council to assert their stance on how migrant workers should be incorporated into the larger community, and even engaging Mayor John Paterson in the study would each provide illuminating insight into the town's official stance on the issues. Furthermore, it would be ideal to include opinions from business owners in Uptown Leamington such as Tony from Tony's Tacos among others such as nightclub staff, ethnic grocery store workers, and older establishments about their take on the 'revitalization versus deterioration' debate about the neighborhood. Lastly, an important addition to the research would be collecting adequate data to facilitate the analysis the differences in male and female respondent's opinions. Since the harassment seemed to be targeted at women, a larger sample size could infer some conclusions about whether women were more adverse to Uptown Leamington than men, for instance, among other possible lines of investigation.

The community-driven perspective of approaching SAWP issues should be furthered. Future research should be done regarding the social reality of migrant-community relationships 
in order to unpack the experiences of migrants in Canada. An ideal study would improve upon several aspects of this exploratory research. In a future iteration of the survey, questions that prompt community members to describe possible strategies for mitigating social tensions with migrant workers would be included. The focus of this current questionnaire involved a large amount of discussion of negative experiences with migrant workers (i.e. asking about 'troubling experiences') and it would be ideal further down the road to balance that aspect with the opportunity to share ideas about positive experiences and possible solutions to social issues. 


\section{Appendix}

\section{Appendix A}

Figure 1: Proportion of the population living in rural areas, Canada, 1851 to 2011

\section{Figure 1}

Proportion of the population living in rural areas, Canada, 1851 to 2011

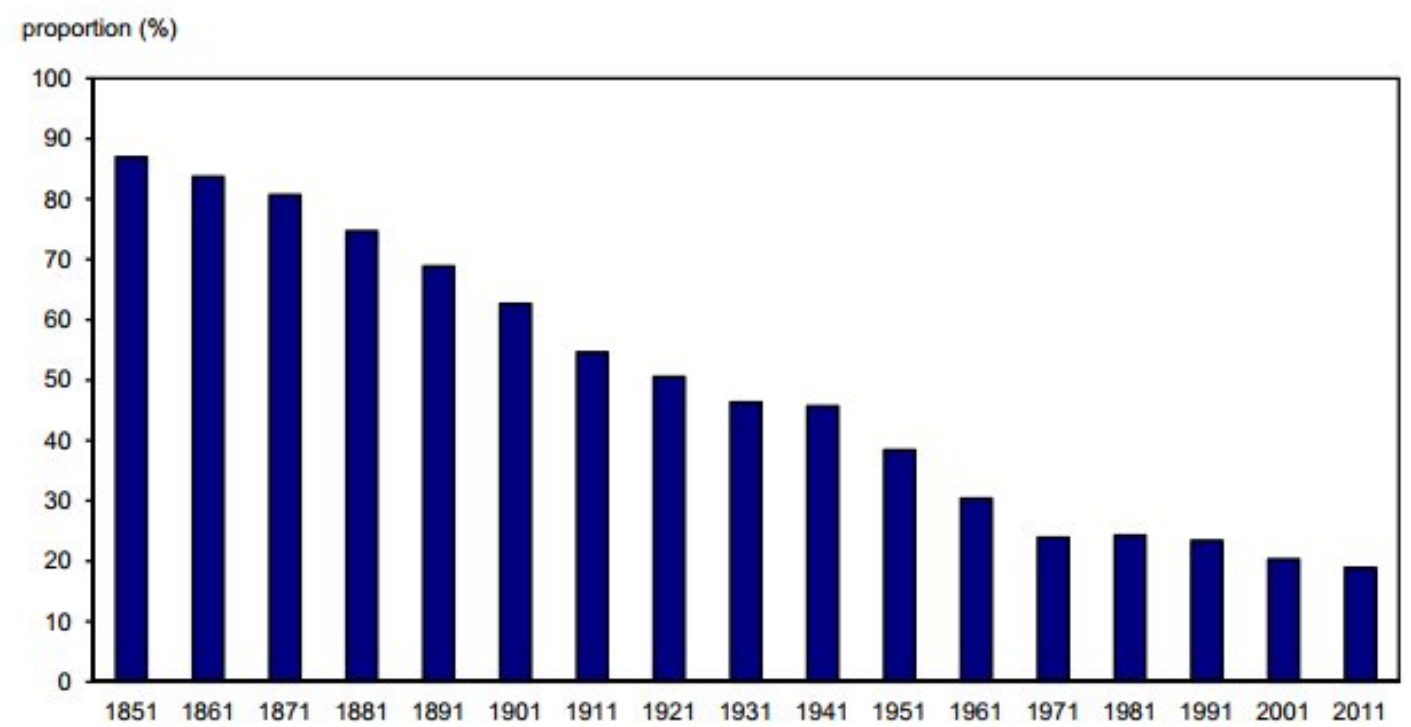

Note: Data presented for 1851 to 1951 censuses are based on the definition of rural areas at that time. Sources: Statistics Canada, censuses of population, 1851 to 2011.

Figure 2: Canadian Urban and Rural Populations, 1851-2006

\section{Canadian Urban and Rural Populations, 1851 to 2006}

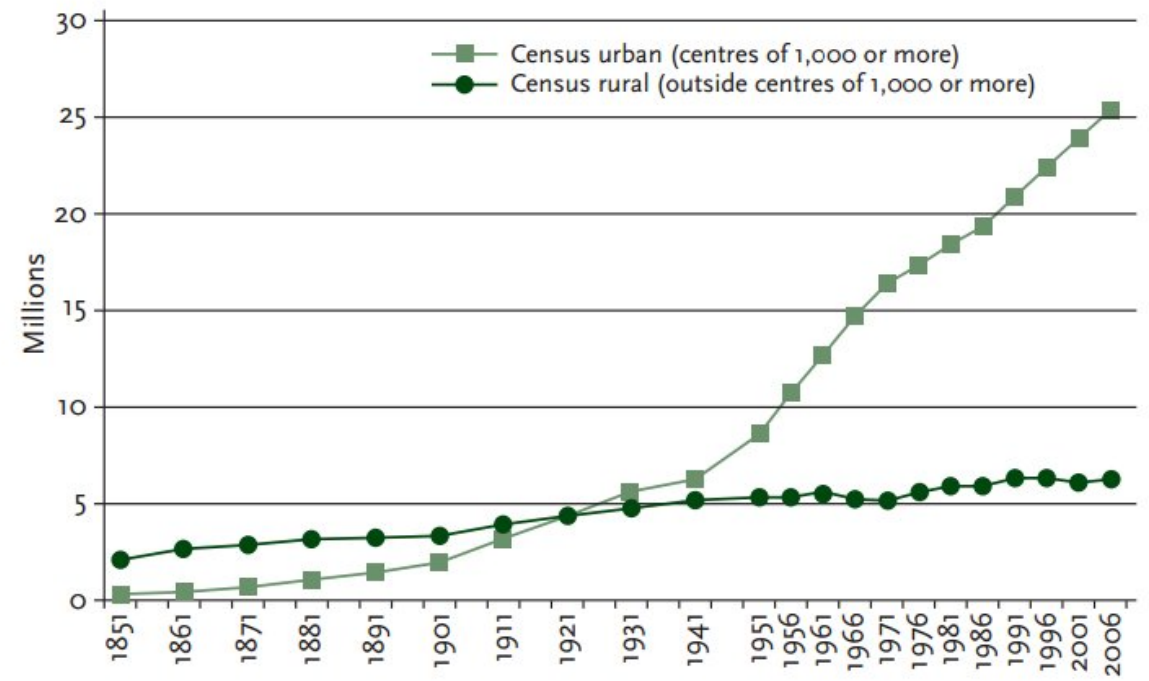


Figure 3: Essex County, Ontario

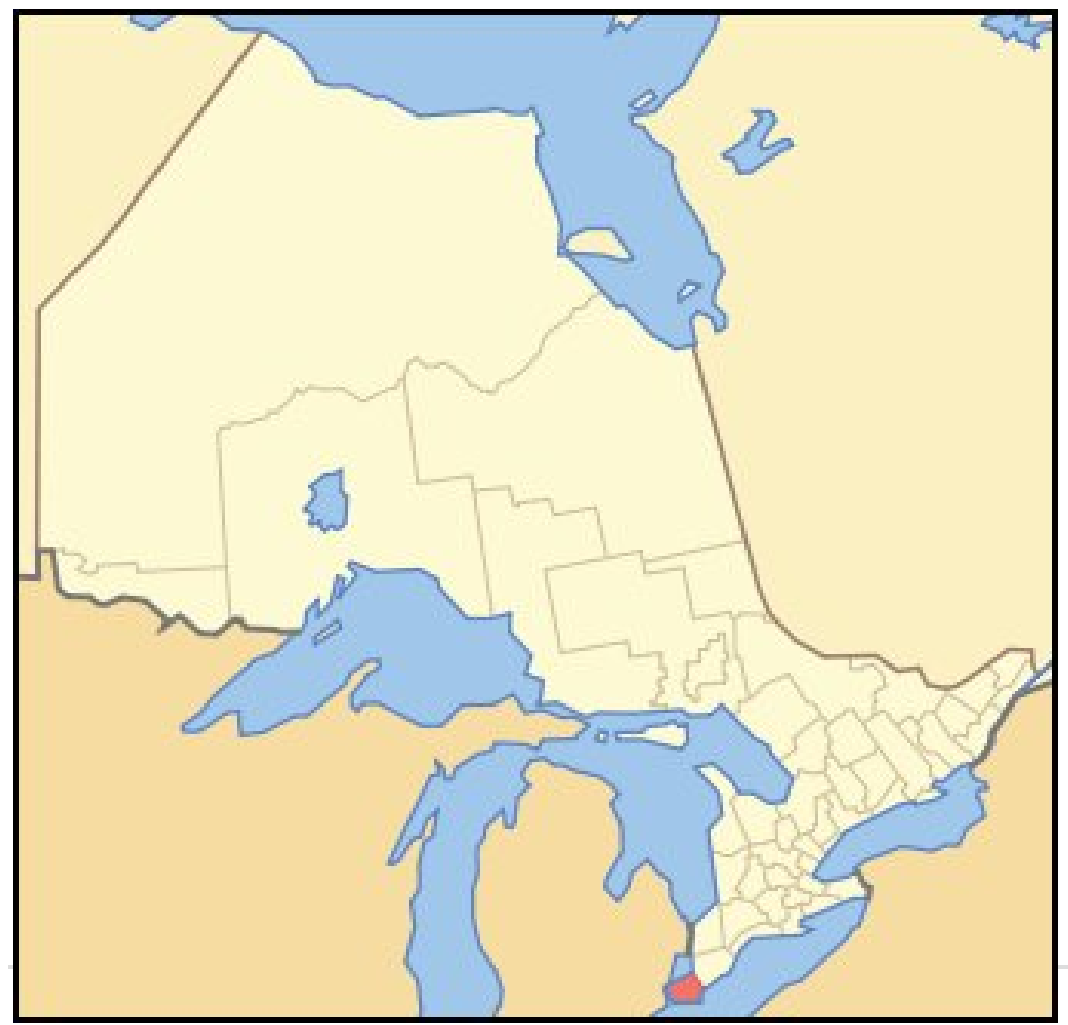

http://en.wikipedia.org/wiki/Essex_County,_Ontario

Figure 4: County of Essex

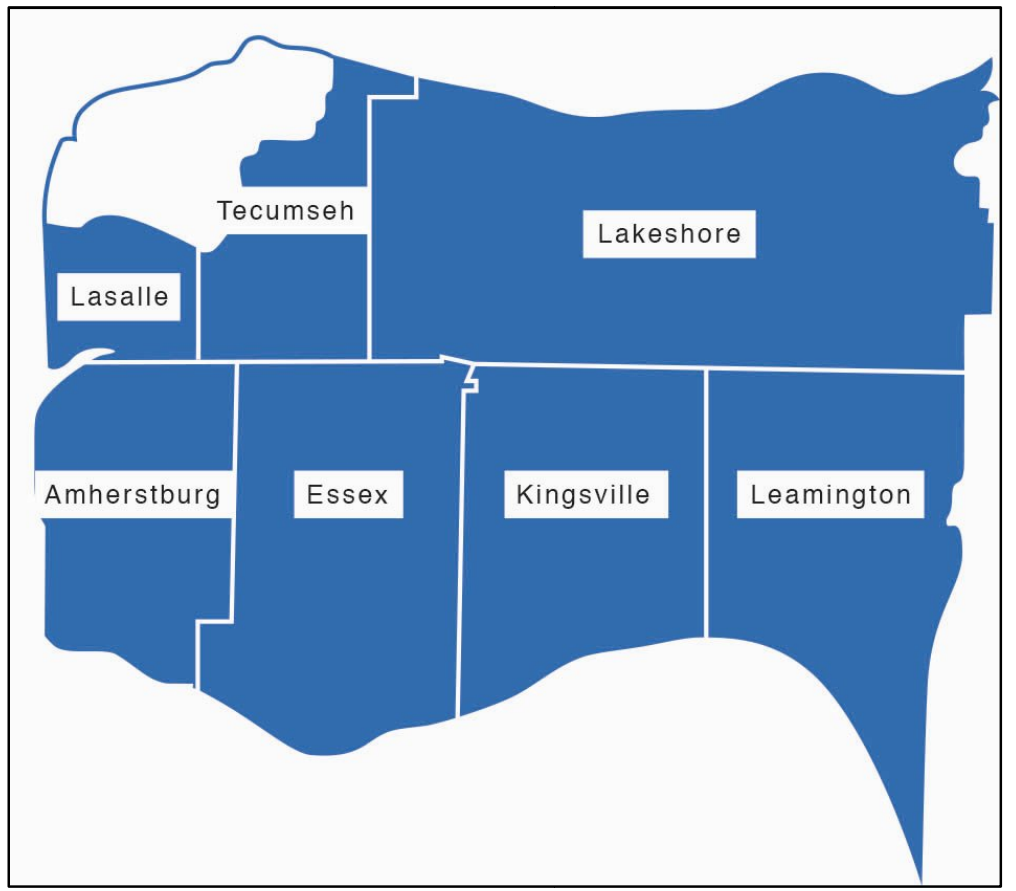

http://www.countyofessex.on.ca/en/index.asp 


\section{Appendix B}

RYERSON

UNIVERSITY

\section{Leamington Research Questionnaire}

Please answer the following questions to the best of your abilities. This survey is estimated to take about 15 to 30 minutes to complete. If you do not wish to answer a question for any reason, please simply skip the question. If you require more room to answer any of the questions, please write on the blank page at the end of the survey. If you are completing this questionnaire on your computer, please continue typing underneath the related question. For participants completing this study on the computer, please click the appropriate box to indicate your answer.

1. Please indicate your age category:

$\square$ 19-30 years of age

$\square 31-40$

$\square 41-50$

$\square 51-60$

$\square 61-70$

$\square 70+$

$\square$ I prefer not to disclose

2. Please indicate your gender:

Male

Female

Other

I prefer not to disclose

3. In what country were you born?

4. Are you now, or have ever been, a landed immigrant in Canada? (A landed immigrant (permanent resident) is a person who has been granted the right to live in Canada permanently by immigration authorities.)

$\square$ Yes

No

$\square$ I prefer not to disclose 
5. What is the highest level of education you completed?

$\square$ Elementary school

Some high school

High school diploma

College

University bachelor degree

Masters' degree

$\mathrm{PhD}$

$\square$ Other:

6. What is your occupation?

7. Do you currently live in Leamington or the Leamington area?

$$
\text { Yes - for how long? }
$$

No

8. If you answered "no" to question number 7, when did you last live in Leamington or the Leamington area?

9. How often do you see migrant farm workers during the summer?

Daily

$\square$ Weekly

$\square$ A few times a month

$\square$ Rarely (once a month or less)

10. How often do you see migrant farm workers during the winter?

\section{Daily}

Weekly

$\square$ A few times a month

$\square$ Rarely (once a month or less)

11. How often do you interact with migrant farm workers or other temporary foreign workers (i.e. conversations, clients at your place of work, community events, etc.)?

Daily

Weekly

A few times a month

$\square$ Rarely (once a month or less) 
12. I consider myself to be knowledgeable of the following details of the Seasonal Agricultural Workers Program:

Work hours: $\square$ Strongly Agree $\square$ Agree $\square$ Neutral $\square$ Disagree $\square$ Strongly Disagree Job tasks: $\square$ Strongly Agree $\square$ Agree $\square$ Neutral $\square$ Disagree $\square$ Strongly Disagree Housing: $\square$ Strongly Agree $\square$ Agree $\square$ Neutral $\square$ Disagree $\square$ Strongly Disagree Worker rights: $\square$ Strongly Agree $\square$ Agree $\square$ Neutral $\square$ Disagree $\square$ Strongly Disagree

13. Do you think local growers need to hire foreign workers to make sure they have enough employees for seasonal farm work?

\section{$\square$ Strongly Agree}

\section{Agree}

Neutral

Disagree

$\square$ Strongly Disagree

14. Have you ever witnessed or heard of any stories about troubling treatment of the migrant farm workers by their employers in your community? Please briefly elaborate on the experience if possible.

$\square$ Yes

$\square$ No

15. Have you ever witnessed or heard of any stories about troubling treatment of the migrant farm workers by members of the community? Please briefly elaborate on the experience if possible.

$\square$ Yes

$\square$ No

16. Have you ever witnessed or heard of any stories about troubling treatment of members of the community by the migrant farm workers? Please briefly elaborate if possible.

$\square$ Yes

$\square$ No

17. I believe my community should do more to include migrant farm workers in the Leamington community.

$\square$ Strongly Agree 
$\square$ Agree

$\square$ Neutral

$\square$ Disagree

$\square$ Strongly disagree

18. What is your attitude regarding the future of regular, non-temporary employment in Leamington?
Extremely positive
Positive
Neutral
Negative
$\square$ Extremely negative

19. With the sale of the Heinz plant, do you think that the public opinion of temporary foreign workers will change in your community?
$\square$ Yes
$\square$ No
$\square$ Unsure

20. In response to question number 19 , please elaborate on how you think public opinion will or will not change:

21. If you would like to elaborate on any of your responses, or feel that you have more information you would like to share that was not addressed in this questionnaire, please add your thoughts here:

22. If selected, I would be willing to participate in a follow-up interview:

$\square$ Yes

$\square$ No

Thank you very much for your valuable contributions to this research study. Your opinions and experiences will be very useful in gaining a clearer understanding of the impact of different types of employment on the Leamington community. If you wish to contact me with any questions, clarifications, or concerns, please don't hesitate to email me at bjarvis@ryerson.ca or call me at 519-830-7885. 


\section{Appendix C}

Descriptive Table of Participant Demographics

\begin{tabular}{|c|c|c|c|c|c|}
\hline $\begin{array}{c}\text { Participant } \\
\text { Name* }\end{array}$ & $\begin{array}{c}\text { Age } \\
\text { Category }\end{array}$ & Gender & $\begin{array}{c}\text { Highest Education } \\
\text { Level }\end{array}$ & Job/Field & $\begin{array}{l}\text { Years Lived in } \\
\text { Leamington }\end{array}$ \\
\hline James & $70+$ & Male & Bachelor's Degree & $\begin{array}{l}\text { Retired, General } \\
\text { M anager }\end{array}$ & $\begin{array}{l}\text { Childhood and } \\
\text { Retirement }\end{array}$ \\
\hline Jennifer & $41-50$ & Female & Bachelor's Degree & Director, Office Job & 45 \\
\hline Julian & $61-70$ & Male & Bachelor's Degree & Retired, Engineer & $\begin{array}{l}\text { Childhood and } \\
\text { Retirement }\end{array}$ \\
\hline Melissa & $51-60$ & Female & Bachelor's Degree & Accountant & 30 \\
\hline Megan & $31-40$ & Female & Bachelor's Degree & HR Admin & left in 2011 \\
\hline Joshua & $51-60$ & Male & Bachelor's Degree & $\begin{array}{l}\text { Retired, Food } \\
\text { Industry }\end{array}$ & 30 \\
\hline Mary & $41-50$ & Female & Bachelor's Degree & Tourism & 12 \\
\hline Martha & $61-70$ & Female & College Diploma & Store Owner & 62 \\
\hline Darlene & $61-70$ & Female & College Diploma & Retired, Nurse & 2.5 \\
\hline Roberta & $31-40$ & Female & College Diploma & Former bartender & 8 \\
\hline John & $41-50$ & Male & High School & IT & 44 \\
\hline
\end{tabular}

*Participant names have been changed to protect confidentiality 


\section{Reference List}

Agricultural Facts (2009). Essex County Federation of Agriculture. Retrieved from http://www.ecfa.ca/main/index.php?page=faq.php\&category=agfacts.

Basok, T. (2000). Migration of Mexican Seasonal Farm Workers to Canada and Development: Obstacles to Productive Investment. International Migration Review, 34(1), 79-97.

Basok, T. (2002). Tortillas and Tomatoes: Mexican Transmigrant Harvesters in Canada. Mcgill: Queen's Press.

Basok, T., Belanger, D., Rivas, E. (2013). Choosing to Become Unauthorized: A Case Study of Mexican Migrant Farm Workers in Leamington. CERIS, Working Paper. Retrieved from http://www.ceris.metropolis.net/wp-content/uploads/2013/02/Final-Report-Basok.pdf.

Basok, T., Binford, L. (2004). Contract labour in Canada and the United States: A critical appreciation of Tanya Basok's Tortillas and tomatoes: Transmigrant Mexican harvesters in Canada. Canadian Journal of Latin American \& Caribbean Studies, 29: 289-308.

Binford, L. (2006). The Seasonal Agricultural Workers Program and Mexican Development. Canadian Foundation for the Americas, 1-16.

Black, K. (2013, August 29). Jamaican Workers Concern Police Board. Blackburn News. Retrieved from http://blackburnnews.com/windsor/windsor-news/2013/08/29/jamaicanworkers-concern-police-board/.

Brem, M. (2006). Migrant workers in Canada: A review of the Canadian Seasonal Agricultural Workers Program. The North-South Institute. Retrieved from http://www.nsi-ins.ca/wp-content/uploads/2012/10/2006-Migrant-Workers-in-Canada-Areview-of-the-Canadian-Seasonal-Agricultural-Workers-Program.pdf

Brownell, C. (2014, May 8). Data on region's temporary foreign workers elusive. The Windsor Star. Retrieved from http://blogs.windsorstar.com/news/data-on-regionstemporary-foreign-workers-elusive.

Burns, P., Gimpel, J. (2000). Economic insecurity, prejudicial stereotypes, and public opinion on immigration policy. Political Science Quarterly 115(2), 201-225.

Canada's rural population since 1851. (2011). Statistics Canada. Retrieved from http://www12.statcan.gc.ca/census-recensement/2011/as-sa/98-310-x/98-310x2011003_2-eng.pdf.

Canadian Council for Refugees. (2010). "Immigration Policy Shifts: From nation building to temporary migration." Canadian Issues, Spring: 90-93. 
Chaccon, O. (2011). Globalization, Obsolete and Inhumane Migratory Policies, and Their Impact on Migrant Workers and Their Families in the North and Central American/Caribbean Region. Journal of Poverty, 15(4): 465-474.

Chandler, G. (2006). Selling the Prairie Good Life. The Beaver, 86(4): 24-30.

Chavez, M., Wampler, B., Burkhart, R. (2006). Left Out: Trust and Social Capital Among Migrant Seasonal Farmworkers. Social Science Quarterly, 87(5), 1012-1029.

Chung, J., Monroe, G. (2003). Exploring Social Desirability Bias. Journal of Business Ethics, 44(4), 291-302.

Clarke, J., Brown, D. (1981). Focii of Human Activity, Essex County, Ontario, 1825-52: Archival Sources and Research Strategies. Archivaria, 12, 31-57.

Clarke, J. (2002). Land, Power, and Economics on the Frontier of Upper Canada. McGill Queen's University Press.

Clemens, M. (2012). Do Farm Workers from Developing Countries Take Jobs from Americans? Center for Global Development.

Colby, C. (1997). From Oaxaca to Ontario: Mexican contract labour in Canada and the impact at home. Davis, CA: California Institute for Rural Studies.

Davidson, T., Davidson, K. (2009, August 26). Leamington, Ontario: Bloom or Bust. Candian Dimension. Retrieved from http://canadiandimension.com/articles/2479/.

Early Municipal History. (2014). County of Essex. Retrieved from http://www.countyofessex.on.ca/en/government/essex-county-first-to-be-settled-inontario.asp.

Flecker, K. (2011). Canada's Temporary Foreign Worker Program (TFWP): Model Program Or Mistake? Canadian Labor Congress. Retrieved from http://www.canadianlabour.ca/sites/default/files/pdfs/model-program-or-mistake-2011en.pdf.

Garcia-Colon, I., Melendez, E. (2013). Enduring Migration: Puerto Rican Workers on U.S. Farms. Centro Journal, 25(2), 96-119.

Gordon, A. (2013, December 20). At St. Jacobs market, a new building rises from the ashes. The Toronto Star. Retrieved from http://www.thestar.com/life/2013/12/20/at_st_jacobs_market_a_new_building_rises_fro $\underline{\text { m_the }}$ ashes.html/

Hallet, M.C. (2012). 'Better than White trash': Work ethic, Latinidad and Whiteness in rural Arkansas. Latino Studies 10(1-2), 81-106. 
Harrison, D. (2013). Optimizing energy options: It's only one of several trends in Leamington region review. Greenhouse Canada Magazine. Retrieved from http://www.greenhousecanada.com/content/view/1190/38/.

Hennebry, J. (2012). Permanently Temporary? Agricultural Migrant Workers and Their Integration in Canada. IRPP Study, 26.

Hennebry, J., Preibisch, K. (2010). A Model for Managed Migration? Re-Examining Best Practices in Canada's Seasonal Agricultural Worker Program. International Migration, 50(1), 19-40.

Keller, J., Patten, M. (2008, July 14). Local food diet possible amid urban sprawl, but Canadians face challenges. The Canadian Press. Retrieved from http://www.torontoenvironment.org/newsroom/teainthenews/greenbelting/20080715.

Koc, M. (2012). Globalization of Food. Canadian Journal of Sociology, 37(2), 213-216.

Koc, M. (2009). Hunger and Plenty: Fragmented Integration in the Global Food System. In A. Denis and D.K. Fishman (Eds.). The New ISA Handbook in Contemporary International Sociology: Conflict, Competition, Cooperation (pp. 323-335). Thousand Oaks, Ca: Sage.

Mas, S. (2014, July 31). Temporary foreign worker agency Actyl Group sues McDonald's Canada. CBC News. Retrieved from http://www.cbc.ca/news/politics/temporary-foreignworker-agency-actyl-group-sues-mcdonald-s-canada-1.2723240

McLaughlin, J. (2009). Trouble in our Fields: Health and Human Rights among Mexican and Caribbean Migrant Farm Workers in Canada. Dissertation, University of Toronto (Canada), Ann Arbor.

McLaren, L. (2003). Anti-Immigration Prejudice in Europe: Contact, Threat Perception, and Preferences for the Exclusion of Migrants. Social Forces, 81(3), 909-936.

Meertens, R., Pettigrew, T. (1997). Is Subtle Prejudice Really Prejudice? The Public Opinion Quarterly, 61(1), 54-71.

Muller, B. (2008). Still Feeding the World? The Political Ecology of Canadian Prairie Farms. Anthropologica, 50(2), 389-407.

Mysyk, A., England, M., Gallegos, J. (2009). A Case for Certified Interpreters for Participants in the Canada/Mexico Seasonal Agricultural Workers Program. Human Organization, 68(3), 318-327.

Native Territories (Approximate), 1600. (2006). City of Toronto Culture Division. Retrieved 
from

http://www1.toronto.ca/wps/portal/contentonly?vgnextoid=dd058d577e312410VgnVCM 10000071d60f89RCRD.

New TV Series captures B.C. town's attempt at 100-Mile Diet. (2009, April 02). CBC News. Retrieved from http://www.cbc.ca/news/arts/new-tv-series-captures-b-c-town-s-attemptat-100-mile-diet-1.801322.

Open Letter to the Mayor of Leamington John Paterson over Recent Comments on 'Jamaican' Migrant Workers. (2013). Justice for Migrant Workers (J4MW). Retrieved from http://j4mw.tumblr.com/post/60232699417/open-letter-to-the-mayor-of-leamington-johnpaterson.

Pang, M. (2013). Temporary Foreign Workers. (Report No. 2013-11-E). Parliament of Canada. Retrieved from http://www.parl.gc.ca/Content/LOP/ResearchPublications/201311-e.htm\#a8.

Parr, J. (1994). Labouring Children: British Immigrant Apprentices to Canada, 1869-1924 (3 ${ }^{\mathrm{rd}}$ Ed.). University of Toronto Press, Toronto. Web.

Perry, A. (2012). Barely legal: Racism and migrant farm labour in the context of Canadian multiculturalism. Citizenship Studies, 16(2), 189-201.

Pratt, S. (2009, July 13). Farming in the city: The local food movement is putting down deep roots, spreading from restaurants and backyards to new business models for farmers and consumers. CanWest News.

Preibisch, K. (2004). Migrant agricultural workers and processes of social inclusion in rural Canada: Encuentros and desencuentros. Canadian Journal of Latin American \& Caribbean Studies, 29(57/8), 203-239.

Preibisch, K., Encalada Grez, E. (2010). The Other Side of el Otro Lado: Mexican Migrant Women and Labor Flexibility in Canadian Agriculture. Signs, 35(2), 289-316.

Read, J., Zell, S., Fernandez, L. (2013). Migrant Voices: Stories of Agricultural Migrant Workers in Manitoba. Canadian Centre for Policy Alternatives, 1-5.

Recognizing farmers' markets in BC and Ontario: Natural life readers' choice award. (2001). Natural Life, 22.

Rural Canada by the Numbers. (n.d.). Federation of Canadian Municipalities. Retrieved from https://www.fcm.ca/Documents/backgrounders/Rural_Canada_by_the_Number_EN.pdf

Sahoye, J. (2013). Mayor blasted for insensitive comments about Jamaicans. The Caribbean Camera. Retrieved from http://thecaribbeancamera.com/?p=1662. 
Shreve, E. (2014, April 16). Approximately 16,000 foreign workers arriving in Ontario. Chatham Daily News. Retrieved from http://www.chathamdailynews.ca/2014/04/16/approximately-16000-foreign-workersarriving-in-ontario.

Smith-Carrier, T., Bhuyan, R. (2010). Assessing the impact of neoliberalism on citizenship: The stratification of social rights by immigration status in Toronto, Ontario. University of Toronto. Retrieved from http://www.yorku.ca/raps1/events/pdf/Smith_Carrier_Bhuyan.pdf.

The Status of Migrant Farm Workers in Canada 2010-2011. (2012). United Food and Commercial Workers Union. Retrieved from http://www.ufcw.ca/templates/ufcwcanada/images/awa/publications/UFCWStatus_of_MF_Workers_2010-2011_EN.pdf.

Trivette, S. (2012). Close to home: The drive for local food. Journal of Agriculture, Food Systems, and Community Development, 3(1), 161-180.

Vermeir, I., Verbeke, W. (2006). Sustainable Food Consumption: Exploring the Consumer "Attitude-Behavioural Intention" Gap. Journal of Agricultural and Environmental Ethics, 19(2), 169-194.

Walia, H. (2010). Transient servitude: migrant labour in Canada and the apartheid of citizenship. Race and Class, 52(1), 71-84.

Watson, H.G. (2012, June 26). Culture Clash. UWindsor The Lance. Retrieved from http://uwindsorlance.ca/2012/06/26/culture-clash/.

Wiebe, N. (2012). Crisis in the Food System: The Farm Crisis. Koc, M., Summer, J., Winson, A. (Eds.), Critical Perspectives in Food Studies (pp. 155-170). Don Mills, ON: Oxford.

Wilhelm, T. (2013, August 30). Sexually aggressive migrant workers affecting life in Leamington. The Windsor Star. Retrieved from http://blogs.windsorstar.com/news/sexually-aggressive-migrant-workers-affecting-life-inleamington.

Worswick, C. (2010). Temporary Foreign Workers: An Introduction. Canadian Issues, Spring 2010, 3-9. 